\title{
Decomposing East-Asian winter temperature and monsoonal circulation changes using timeslice experiments
}

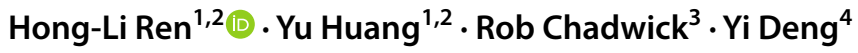

Received: 13 July 2019 / Accepted: 27 December 2019 / Published online: 17 January 2020

(C) The Author(s) 2020

\begin{abstract}
Based on a set of pilot atmosphere-only experiments from the Cloud Feedback Model Intercomparison Project Phase 3 (CFMIP-3), in this study, the winter surface air temperature (SAT) and monsoonal circulation changes in East Asia as a response to the $4 \times \mathrm{CO}_{2}$ forcing in coupled model are decomposed into the four parts in terms of the responses to the uniform SST warming, $4 \times \mathrm{CO}_{2}$ radiative effect, SST pattern changes, and plant physiological effect. The uniform SST warming presents the most significant influence on the increase of SAT change, which strengthens the East Asian winter monsoon (EAWM) circulation. The $\mathrm{CO}_{2}$ radiative effect can also induce the SAT increase over East Asia but with a magnitude smaller compared to the uniform SST warming, in which more warming is in land than ocean and the EAWM circulation could be weakened consequently due to the decreased land-sea thermal contrast in response to the $\mathrm{CO}_{2}$ radiative effect. The SAT changes in response to the SST pattern change show inconsistencies over the eastern and southern parts of East Asia between the two models, associated with the large difference for EAWM circulation changes, indicating that the SST pattern change could be the primary source of inter-model uncertainties in the East-Asian SAT change. As for the influence of plant physiological effect, it could generate a SAT rise in many highly vegetated regions. Further analyses for different areas show that both the uniform SST warming and $\mathrm{CO}_{2}$ radiative effects could induce more intense SAT increase in northern East Asia, while the plant physiological effect has a more significant influence on that in southern/eastern part of East Asia.
\end{abstract}

Keywords CFMIP-3 $\cdot$ Surface air temperature change $\cdot$ Response $\cdot$ EAWM $\cdot$ Uncertainty

\section{Introduction}

The Fifth Assessment Report (AR5) (2013) from the Intergovernmental Panel on Climate Change (IPCC) demonstrates that global surface air temperature (SAT) has risen since 1901 , and the period of 1983-2012 was likely to be the warmest 30 years in the past 1400 years in the northern

Hong-Li Ren

renhl@cma.gov.cn

1 Department of Atmospheric Science, School of Environmental Studies, China University of Geosciences, Wuhan 430074, China

2 Laboratory for Climate Studies and CMA-NJU Joint Laboratory for Climate Prediction Studies, National Climate Center, China Meteorological Administration, Beijing 100081, China

3 Met Office Hadley Center, Exeter, UK

4 School of Earth and Atmospheric Sciences, Georgia Institute of Technology, Atlanta, GA, USA hemisphere. The greenhouse gases (GHGs), like $\mathrm{CO}_{2}$, have shown an increasing trend, particularly in the most recent 50 years (Guoyu 2008). As is well known, the East Asian monsoon system is one of the most important parts of the climate system, and many countries including China, Japan, and Korea are influenced by it. Therefore, there has been a great amount of research into SAT change in response to $\mathrm{CO}_{2}$ concentration rising over East Asia in the past decades.

The SAT changes over East Asia under future emission scenarios have been assessed in many studies. Zhou and $\mathrm{Yu}$ (2006) indicated that the GHGs contribute to the SAT variation over China in the last half of the twentieth century. The projected SAT rise results from increased longwave radiation at the surface and related feedbacks, which is associated with $\mathrm{CO}_{2}$ concentration rising (Lee et al. 2013). As emissions increase, the enhanced warming has been confirmed. Under the IPCC AR5 scenarios, warming increased with latitude, ranging from 1 to $3{ }^{\circ} \mathrm{C}$ for the average from 2071 to 2100 in the Representative Concentration Pathways 4.5 (RCP4.5) projection and from 4 to $9{ }^{\circ} \mathrm{C}$ under the RCP8.5 scenario 
compared with the average from 1971 to 2000 (Wei and Bao 2012). Downscaled simulation results showed the frequency of heat wave events with temperature greater than $30{ }^{\circ} \mathrm{C}$ is projected to increase by $131 \%$ and $111 \%$ in the RCPs 8.5 and 4.5 (Lee et al. 2014), which indicates the character of a higher warming with a higher RCP and is consistent with $\mathrm{Xu}$ and $\mathrm{Xu}$ (2012).

Compared with observational results, the temperature change over East Asia is more complicated and less certain across model projections. The warming intensity over China appears to be greater than the global mean level, and warming in winter is the most significant (Rangwala et al. 2010; Zhang and Tan 2012; Lang and Sui 2013), particularly over land regions (Jiang et al. 2004). According to future climate projections for East Asia, the annual mean SAT increases by $1.8^{\circ} \mathrm{C}$ during $2030-2049$ (Lee et al. 2013). In East Asia, the most significant increase is seen in Southeastern China under future emission scenarios (Seo et al. 2014). Lee et al. (2012) suggested northern East Asia will be subject to increased heat extremes. Based on a set of atmosphere-ocean coupled general circulation models from CMIP5, Yang et al. (2014) indicated that warming is expected all over China, and northern China shows greater warming than southern China, especially the Tibetan region.

As the temperature rises, the oceans are also warming. Bernstein et al. (2008) demonstrated that a global SST increase had been confirmed from observations and the AR5 (2013) indicated the upper ocean was warmer and experienced a $0.11^{\circ} \mathrm{C}$ increase per decade during $1971-2010$. As a result, the increased SST and the different SST pattern changes could cause a series of climate effects. The changes of SST in distinct areas could drive anomalous heat transport, as well as circulation changes (Xie et al. 2010). From a global perspective, a strengthening of land-sea thermal contrast in transient simulations of coupled models could be attributed to the spatially uniform warming in response to the SST increase (Takakuwa and Kina 2014). Based on a set of coupled biosphere-atmosphere model, Sellers et al. (1996) found that the doubled $\mathrm{CO}_{2}$ concentration will reduce evapotranspiration, leading to the increased air temperature over the tropical continents. Boucher et al. (2009) and Chadwick (2015) reached similar conclusions in their studies.

Temperature variability over East Asia region is closely accompanied by various changes of general circulation, which makes analysis of the connected mechanisms much more complicated. During warm (cold) winters, a positive (negative) SST anomaly appears in marine East Asia and a negative (positive) SST anomaly appears in the Philippine Sea, and the SST changes for distinct regions could generate circulation anomalies (Hsu et al. 2001; Dong et al. 2009).

The cold surges can be caused by the upper-level blocking originated from North Pacific (Park et al. 2008). The effect of the Arctic Oscillation on winter temperature over East
Asia could be changed depending on the phase of the Western Pacific pattern in North Pacific (Park and Ahn 2016). Along with the decadal variability of the Hadley Circulation (HC), its linkage to the SAT change in East Asia showed decadal variations as well, from the weak to strong relationship. Such a change could be related to the interaction between the $\mathrm{HC}$ and the general circulation system over the Philippines, associated with the East Asian winter monsoon (EAWM) (Zhou and Wang 2008).

EAWM is an important component of climate system due to its great influence on the winter climate variations over East Asia. The atmospheric moisture, precipitation, and temperature changes are connected with the EAWM (Chen et al. 2013; Ding et al. 2014; Gong and Wang 2003), and previous studies have shown that the EAWM can be influenced by various factors. As we know, the surface heating is characterized by the seasonal variation and the land-sea difference, which should be the nature of the formation of trade winds, and the asymmetrical solar heating generated by the zonal and meridional asymmetric land-sea distribution also have influence on the variation of monsoon (Halley $1686,1735)$. The key driving force for the EAWM is the available potential energy generated by the differential heating between land and sea (Zhang et al. 1997; Jhun and Lee 2004). Further studies show that in addition to the seasonal variation of land-sea contrast, the changes of radiation and general circulation contribute to the variation of monsoon as well (Dao and Chen 1957). According to Xiao et al. (2016), warmer SST in the late 1990s over the North Atlantic could have led to a stronger EAWM, and the reduced sea ice in the Arctic Ocean and the increased snow cover in the Eurasian Continent are also possible causes of the interdecadal change in the EAWM. In addition, the changes of middle-high latitude circulation can also generate the EAWM anomalies. The planetary wave activity may induce variations in the Arctic Oscillation, Siberian High, and the Aleutian Low, leading to anomalous EAWM (Chen et al. 2013; Chen et al. 2008; Tan and Chen 2014), and the climate modes are also influenced by distinct external forcings (Huang et al. 2018; Cattiaux and Cassou 2013).

Under the background of climate change, the current skill of seasonal and regional climate predictions is not enough yet to meet various needs from industrial and public sectors (Park et al. 2016; Seo et al. 2014; Jeong et al. 2017), partly due to deficiencies of climate models. The correlation between the observed and simulated China SAT for 1880-1999 is still lower than that for either the global or Northern Hemispheric average, and thus the mechanisms leading to this warming remain an open question (Zhou and Yu 2006). Guoyu (2008) indicated that the uncertainties of climate warming could be generated by the biases from observation data, the unclear mechanisms of climate systems, such as cloud feedback, and the imperfect model 
simulations. Owing to the complex topography in East Asia, simulations have difficulty capturing the responses well (Fang et al. 2011). In addition, seasonal climate variability in East Asia is strongly influenced by many internal and external factors including the East Asian monsoon, tropical ocean variability, and other atmospheric low-frequency modes. Therefore, a comprehensive understanding of these factors is essential for better seasonal climate predictions, as well as future climate projections over East Asia (Ding et al. 2014; Jeong et al. 2017; Luo and Wang 2017).

The CFMIP-3 mainly focuses on the scientific questions, such as how the earth system responds to forcings, where the model biases come from, how the climate will change under future scenarios, and which are exactly the major issues occurring in climate researches over East Asia. In this study, a set of timeslice experiments from CFMIP-3 are applied in East Asia to examine (1) winter SAT changes in response to different aspects of $\mathrm{CO}_{2}$ forcing and SST changes, (2) the possible mechanisms of temperature changes in response to these different forcings, and (3) which aspect is probably the main cause of uncertainty in inter-model projections over East Asia. The remainder of the paper is organized as follows. Experiment design including data and method is introduced in Sect. 2. Section 3 describes the features of SAT changes over East Asia in each experiment. In Sect. 4, analysis of winter SAT for different East-Asian areas are depicted. The EAWM changes are presented in Sect. 5. In Sect. 6, the possible mechanisms of SAT changes in response to the different forcings are investigated in detail, and the summary and discussions are given in Sect. 7.

\section{Models, experiments, and methods}

\subsection{Models}

In this study, monthly mean outputs from the two climate models, HadGEM2-ES, CCSM4 and associated experiments, are used (Table 1) to estimate winter SAT change over East Asia. Notice that there are three models in this set of pilot experiments, HadGEM2-ES, CCSM4 and CNRM, but the experimental design of CNRM is slightly different from the other two models, so we abandoned the analysis for CNRM, and this part will be introduced in Sect. 2.2. Since the horizontal resolutions of the models are different, both of the model data have been interpolated into a $1.25^{\circ} \times 1.25^{\circ}$ grid before analysis for comparison with each other. We have evaluated that the two models can reasonably capture the main climatological characteristics of winter temperature and circulation fields in East Asia compared to observation (figures not shown).

\subsection{Experiments}

In order to effectively estimate winter SAT changes over East Asia in response to different forcings, a set of pilot atmosphere-only experiments from CFMIP-3 is applied in this study, which are specifically designed to decompose the response to $4 \times \mathrm{CO}_{2}$ forcing, relative to preindustrial level, in coupled models into the different aspects as follows:

(1) piSST — an atmosphere-only experiment with monthlyvarying SSTs and sea-ice from the years of piControl parallel to years 101-130 of each model's own abrupt 4 $\times \mathrm{CO}_{2}$ run (Webb et al. 2013; Chadwick et al. 2017).

(2) piSST $4 \mathrm{~K}$ - the same as piSST but with SST uniformly increased by $4 \mathrm{~K}$, and sea-ice remains the same as piSST.

(3) piSST $4 \times \mathrm{CO}_{2}$-the same as piSST but the concentration of $\mathrm{CO}_{2}$ is quadrupled, and seen only by the radiation scheme.

(4) piSST $4 \times \mathrm{CO}_{2} \mathrm{Veg}$ - the same as piSST $4 \times \mathrm{CO}_{2}$ but this forcing is seen by both the radiation scheme and the plant physiological effect. Note that dynamical vegetation is turned off and the distribution of plants won't change when the $\mathrm{CO}_{2}$ concentration rises. HadGEM2 and CCSM4 both represent the plant physiological effect but CNRM-CM5 does not, in addition, sea ice is unchanged for all experiments with HadGEM2 and CCSM4, but is allowed to vary in CNRM-CM5 in piSSTFuture and piSST4K experiments. Considering the large discrepancy the result of CNRM could make driven by the lack of physiological effect, we move out the analysis of CNRM, only display the results of HadGEM2 and CCSM4.

(5) piSSTFuture- the same as piSST but with a patterned SST anomaly taken from years 101-130 of each model's own abrupt $4 \times \mathrm{CO}_{2}$ experiment minus piControl, and the global mean SST increase is scaled to be
Table 1 Summary of the two climate models used in this study

\begin{tabular}{lll}
\hline Model & Institute & Resolution \\
\hline $\begin{array}{l}\text { HadGEM2-ES (Hadley Centre Global Environmental } \\
\text { Model version 2 Earth System model) }\end{array}$ & Met Office Hadley Centre & $1.25^{\circ} \times 1.875^{\circ}$ \\
CCSM4 (Community Climate System Model version 4) & $\begin{array}{c}\text { National Center for Atmos- } \\
\text { pheric Research }\end{array}$ & $1.875^{\circ} \times 1.25^{\circ}$ \\
\hline
\end{tabular}


approximately 4K (Chadwick 2015). Sea-ice and $\mathrm{CO}_{2}$ remain the same as piSST.

(6) piSSTTot - the same as piSST, but with monthly-varying SSTs and sea-ice taken from years 101-130 of each model's own abrupt $4 \times \mathrm{CO}_{2}$ experiment minus piControl. $\mathrm{CO}_{2}$ is quadrupled, and is seen by both the radiation scheme and the plant physiological effect.

According to the Intergovernmental Panel on Climate Change (IPCC) Fifth Assessment Report (AR5), the more severe global SAT increase can be seen under a higher emission, and thus it would be suitable to estimate the long-term change and climate sensitivity by the experiments concerning the higher $\mathrm{CO}_{2}$ emission such as abrupt $4 \times \mathrm{CO}_{2}$, compared to the double $\mathrm{CO}_{2}$ scenario ever highly considered before. On the other hand, in CFMIP-3, a series of terms are added to more precisely quantify the contributions of different processes and climate changes underlying cloud feedbacks and adjustments, and these budget terms are requested in the DECK abrupt $4 \times \mathrm{CO}_{2}$ experiment (Webb et al. 2013). Thus, this set of CFMIP-3 experiments are applied to analyze decomposition of the East Asian temperature response to the $4 \times \mathrm{CO}_{2}$ forcing.

In coupled General Circulation Models (GCMs), quadrupled $\mathrm{CO}_{2}$ will induce SST rising, but such an increase does not show a homogeneous distribution. Instead, SST change varies by regions and the global-mean SST increases by about $4 \mathrm{~K}$ in abrupt $4 \times \mathrm{CO}_{2}$ compared to piControl experiment. Therefore, the SST change in a coupled model can be divided into uniform SST warming of $4 \mathrm{~K}$ and SST pattern change. In addition, the increase of the atmospheric $\mathrm{CO}_{2}$ has a direct impact via atmospheric radiative changes, as well as the plant physiological effect associated with narrowing plant stoma, thus reducing transpiration and decreasing atmospheric water availability. By decomposing the $4 \times \mathrm{CO}_{2}$ forcing in a coupled model into the uniform SST warming, $4 \times \mathrm{CO}_{2}$ direct radiative effect, plant physiological effect in response to $\mathrm{CO}_{2}$ concentration rising, and SST pattern change, the winter SAT changes in response to the individual forcing over East Asia and the main causes of them can be estimated.

\subsection{Methods}

In reference to the experimental design, the piSST4K experiment is the same as the piSST experiment except for the $\mathrm{SST}$, so the net response to the uniform SST $+4 \mathrm{~K}$ can be extracted by subtracting piSST from piSST4K. Similarly, the influence of the $4 \times \mathrm{CO}_{2}$ radiation scheme can be examined by taking the difference between piSST $4 \times \mathrm{CO}_{2}$ and piSST. To examine influence of the SST pattern change, we can take the difference between piSSTFuture and piSST4K, and the response to the plant physiological effect can be estimated by subtracting piSST $4 \times \mathrm{CO}_{2}$ from piSST $4 \times \mathrm{CO}_{2} \mathrm{Veg}$. Finally, the total response to the $4 \times \mathrm{CO}_{2}$ forcing, including both SSTs and $\mathrm{CO}_{2}$ effects, can be calculated by subtracting piSST from piSSTTot.

\section{Characteristics of the winter SAT changes over East Asia}

Previous studies have estimated the performance of the two models in reproducing the main features of the East Asian winter temperature and the characteristics of temperature changes proved to be well captured by most of the models from IPCC Third to Fifth Assessment Reports, including HadGEM2 and CCSM4 (Jiang et al. 2016). To further test the simulation capacity of these two models, the average climate state of winter temperature during 1948-2004 in historical experiment for HadGEM2 and CCSM4 are estimated and compared with the observational results. We can see the two models can generally depict the distributions of winter temperature as the observational results show (Fig. 1).

Figure 2 shows distributions of the SAT changes during December, January, and February (DJF) in the two models. We can see that the winter SAT change in response to the uniform SST warming presents a very significant

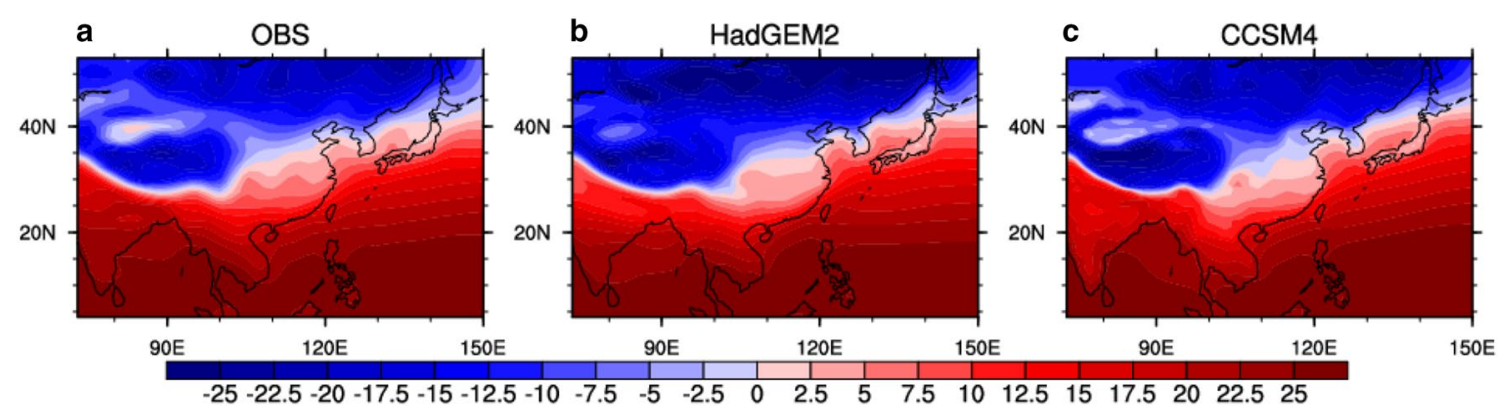

Fig. 1 The averaged winter SAT $\left({ }^{\circ} \mathrm{C}\right)$ in historical experiment for HadGEM2, CCSM4 and observational result during 1948-2004 for NCEP/ NCAR reanalysis 
increase over the whole East Asia in ensemble-mean result (Fig. 2c), and the greatest increase is located over the Qinghai-Tibetan Plateau and northern East Asia. In general, such an increase shows a non-uniform distribution, and the SAT rising is greater in northern than southern East Asia. The increased SAT also appears over East Asia in response to the $4 \times \mathrm{CO}_{2}$ radiative effect, but like the global mean SAT change, with a smaller magnitude than that responding to the uniform SST warming, where the land warms more intensely than ocean (Fig. 2d-f). As we know, $\mathrm{CO}_{2}$ could lead to air temperature and SST rising by its radiative effect. Using this set of atmosphere-only experiments, the influences of SST change and the direct $\mathrm{CO}_{2}$ effect have been individually estimated here. We can clearly see that the uniform SST warming has more significant influence on the SAT change than the $4 \times \mathrm{CO}_{2}$ radiation scheme. Therefore, we may infer that, with $\mathrm{CO}_{2}$ concentration rising, the increased temperature in East Asia as simulated by the GCMs could be mainly caused by the uniform SST warming due to the $\mathrm{CO}_{2}$ concentration rising rather than by the direct radiative effect of the $\mathrm{CO}_{2}$. Previous studies have shown that the enhanced land warming in response to increased SST is related to atmospheric adjustments, which could be attributed to limited moisture availability over land (Joshi et al. 2008; Byrne and O'Gorman 2013) and soil moisture feedbacks (Berg et al. 2016).

In addition, the distribution of SAT change in response to the SST pattern change shows a relatively large inconsistency
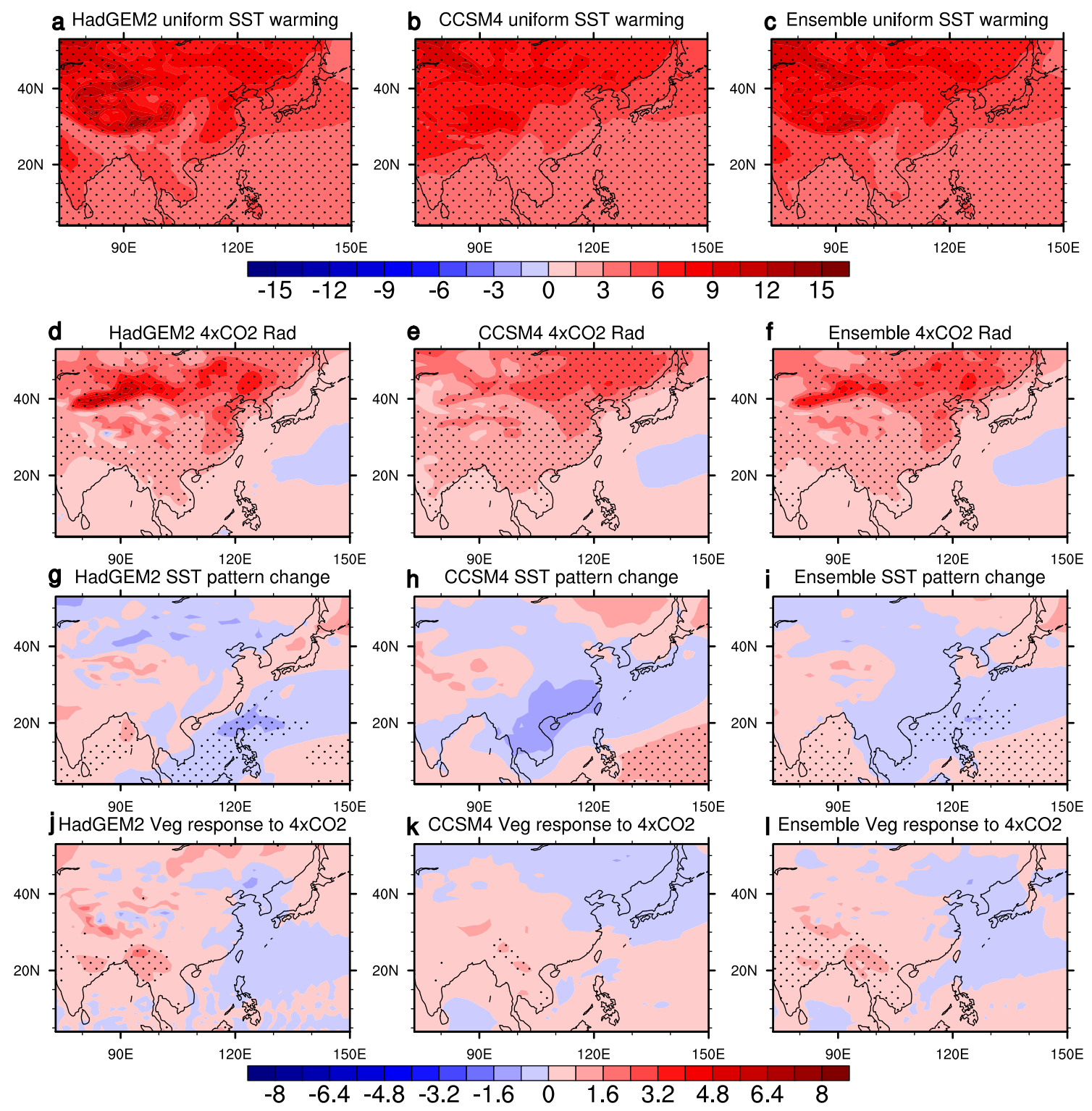

Fig. 2 DJF SAT changes $\left({ }^{\circ} \mathrm{C}\right)$ in response to the uniform SST warming $+4 \mathrm{~K}(\mathbf{a}-\mathbf{c}), 4 \times \mathrm{CO}_{2}(\mathbf{d}-\mathbf{f})$, SST pattern change (g-i), and plant physiological effect $\mathbf{j}-\mathbf{l}$ for HadGEM2, CCSM4, and the ensemble mean, with stippled areas exceeding the $95 \%$ confidence level 

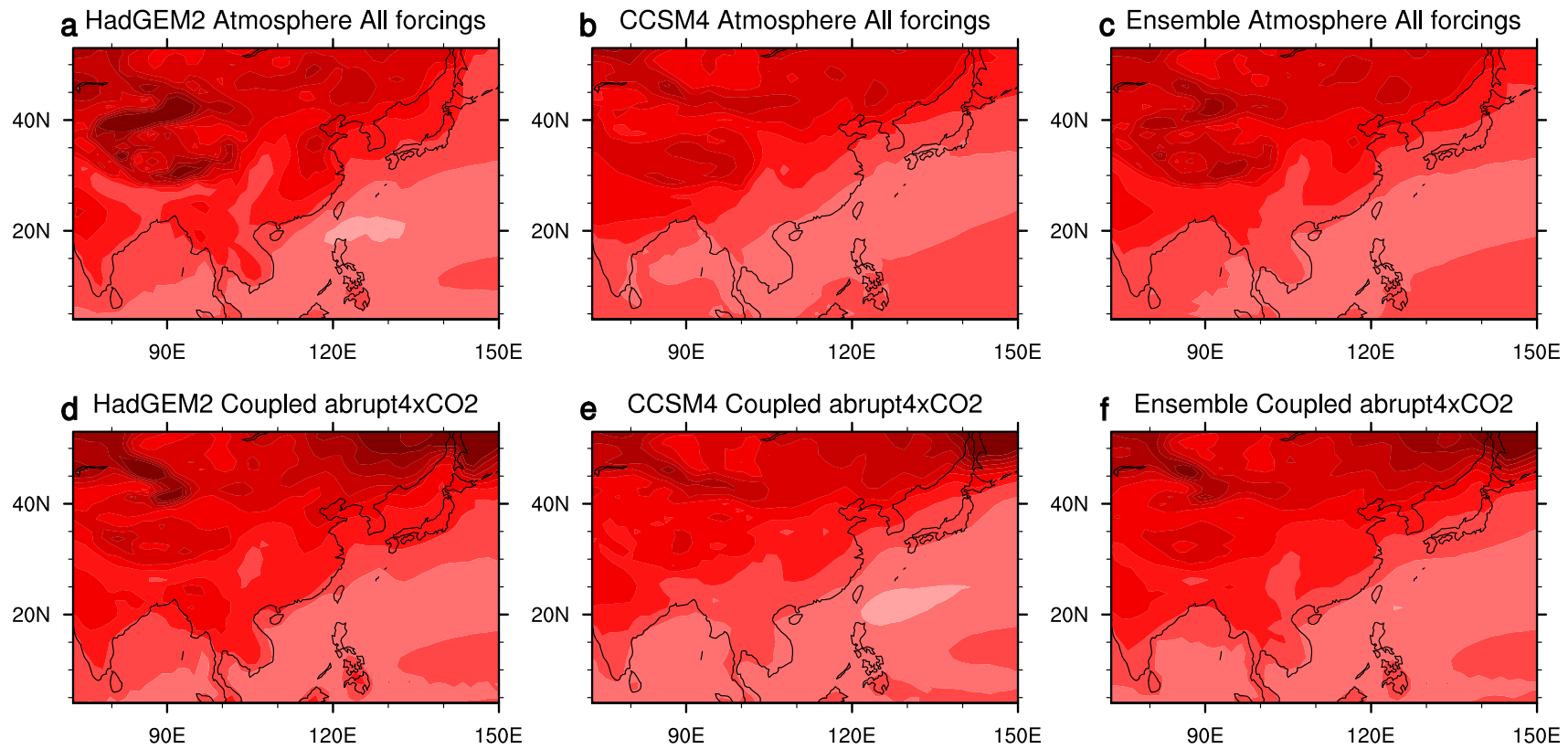

g HadGEM2 Coupled-Atmos.

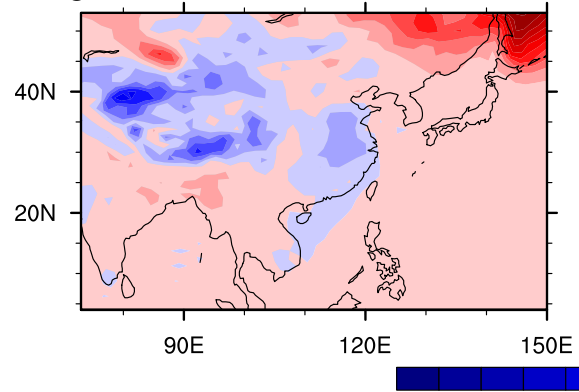

h CCSM4 Coupled-Atmos.
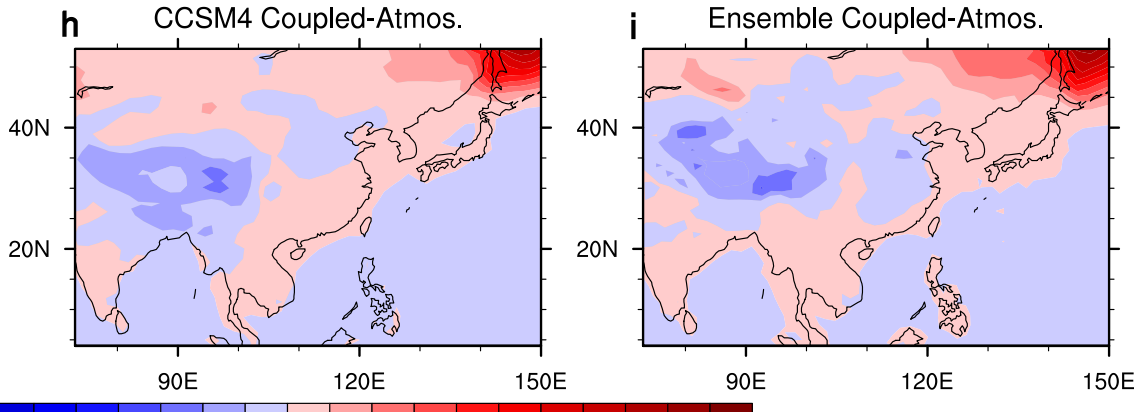

$\begin{array}{lllllllllll}-15 & -12 & -9 & -6 & -3 & 0 & 3 & 6 & 9 & 12 & 15\end{array}$

Fig. 3 The sum of all the individual atmosphere-only components for winter SAT changes over East Asia (a-c), the coupled abrupt $4 \times \mathrm{CO}_{2}$ response $(\mathbf{d}-\mathbf{f})$, and the difference between the coupled model and the sum of components $(\mathbf{g}-\mathbf{i})$

between the two models, which is mainly located in the south and east of East Asia, with a more significant decrease in SAT for CCSM4. From the ensemble mean we can see that the SAT decreases over most parts in the north, east and south of East Asia. As for the response of the plant physiological effect, the ensemble mean result shows the increased SAT located in most parts of land regions, particularly in the south of East Asia (Fig. 2). In general, the uniform SST warming and $\mathrm{CO}_{2}$ radiative effect are the main sources of the SAT rising, and the SST pattern change appears to be the primary reason for the uncertainty between the two models in the SAT changes over East Asia, and the possible reasons for this inconsistency will be discussed later.

In order to test the difference between the coupled models and these atmosphere-only experiments, we calculate the sum of the individual atmosphere-only components for winter SAT changes (Fig. 3a-c), the coupled abrupt $4 \times \mathrm{CO}_{2}$ response (Fig. $3 \mathrm{~d}-\mathrm{f}$ ), and their differences (Fig. $3 \mathrm{~g}-\mathrm{i}$ ). It is seen that the differences are mainly located in the northeast of East Asia and the Qinghai-Tibetan Plateau, where the former shows a higher SAT response and the latter does a lower one for the coupled models. This presumably indicates the nonlinear influence of the different aspects of increased $\mathrm{CO}_{2}$ concentration on SAT in some regions, especially over the above-mentioned regions, while the differences are small in the other areas we focused on in this study. Meanwhile, we take it into account that not all of the coupled models give global warming by exactly $4 \mathrm{~K}$, which could contribute to the uncertainty in regional temperature change. Specifically, the SST rises up to about $3.2 \mathrm{~K}$ in abrupt $4 \times \mathrm{CO}_{2}$ experiment compared with piControl experiment in HadGEM2, while it's $4.4 \mathrm{~K}$ in CCSM4. It is clear that the difference of SST change is about $1.2 \mathrm{~K}$ between the two models, and the assumption of uniform SST warming to $4 \mathrm{~K}$ would lead to the uncertainty of regional temperature change caused by the lower SST change of $0.8 \mathrm{~K}$ in HadGEM2, and the 
higher SST change of $0.4 \mathrm{~K}$ for CCSM4, compared with the coupled runs. On the other hand, to test the validity of the mono-forcing in this study, we further estimate the differences between the sum of all the distinct forcings and the total response to the $4 \times \mathrm{CO}_{2}$ forcing. The differences are relatively minor and negligible for the two models (not shown), which means each of the forcing can be regarded as independently, in other words, the non-linear effects among them can be ignored in this study.

\section{Winter SAT changes over distinct subregions}

The geographical conditions vary greatly across East Asia, leading to the distinct climate characteristics (Zhang et al. 2015; Gao et al. 2016). In order to examine the decompositions of the SAT changes in terms of different areas, the East Asian continent is divided into four major parts in reference to China's National Assessment Report on Climate Change (2007). The four subregions include: northwestern East Asia (NW), northeastern East Asia (NE), southwestern East Asia (SW), and East China (EC), as shown in Fig. 4. The winter SAT changes and their inter-model spreads over four regions are presented in Fig. 5.

In general, we can see in Fig. 5 that the uniform SST warming has the most significant influence on SAT rising in all subregions, and the second is from the $\mathrm{CO}_{2}$ radiative effect. When SSTs uniformly rise by $4 \mathrm{~K}, \mathrm{NW}$ has the largest SAT increase, while the inter-model difference is large in EC and NW. In response to the $4 \times \mathrm{CO}_{2}$ direct radiative effect, the most significant increase of SAT occurs in NW and NE, also with the largest differences across the models for NW. As illustrated in Sect. 3, the projected results have shown the relatively large difference between the two models in NE and EC in response to the SST pattern change, and the SAT changes for all these regions seemed not so remarkable in winter. For the responses to the plant physiological effect, SW shows the largest SAT rising, probably due to the larger

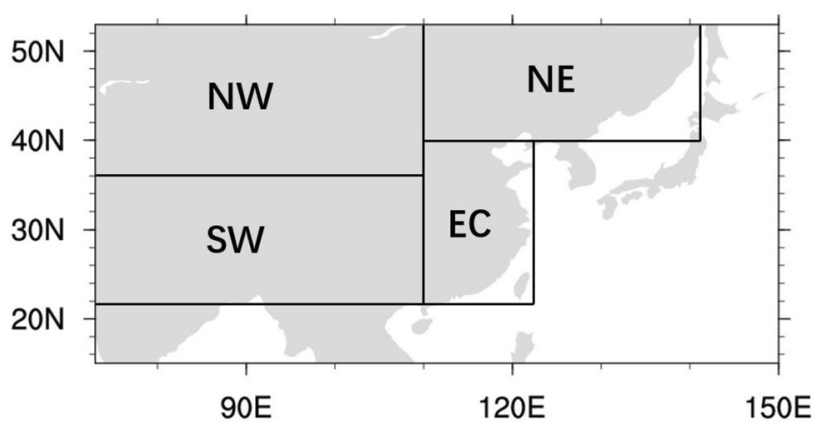

Fig. 4 Domains of the four subregions in East Asia-NW, NE, SW, and EC

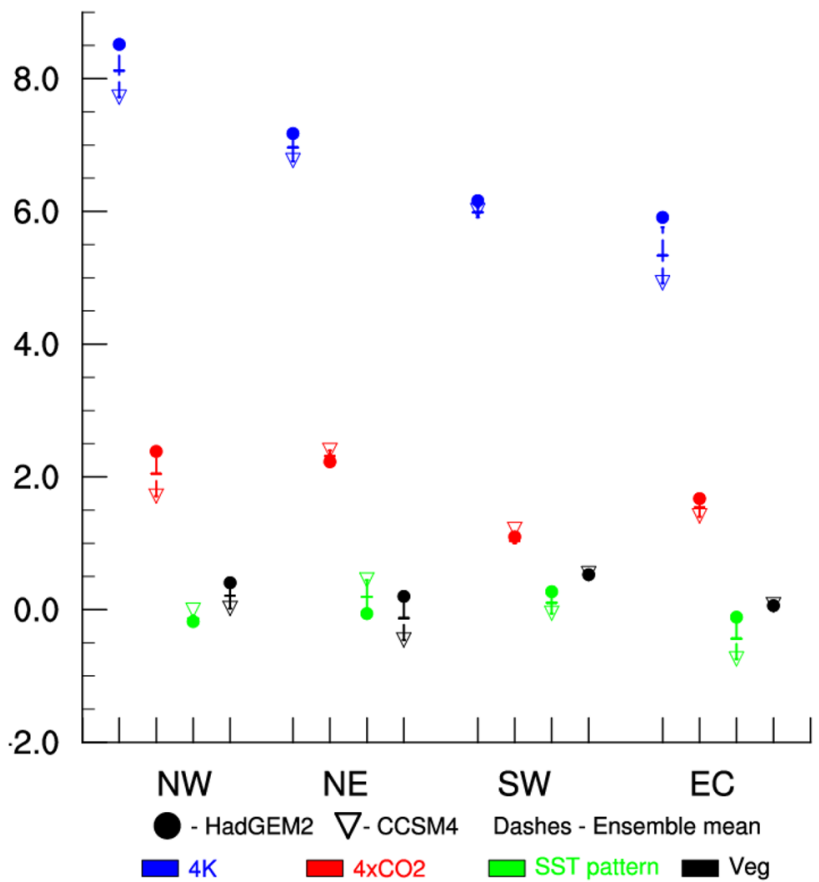

Fig. 5 Winter mean SAT changes $\left({ }^{\circ} \mathrm{C}\right)$ in four regions in response to different forcings. The blue, red, green, and black lines represent errors across models in response to the uniform SST warming $+4 \mathrm{~K}$, $4 \times \mathrm{CO}_{2}$, SST pattern change, and plant physiological effect, where the dots, triangles, and dashes represent HadGEM2, CCSM4, and their ensemble mean, respectively

vegetation coverage in the south and east of East Asia, while the largest inter-model uncertainty lies in NE. As a result, the uniform SST warming and $\mathrm{CO}_{2}$ radiative effect both appear to induce more intense SAT increase over northern East Asia, especially in NW, while the plant physiological effect has a more significant influence on the southwestern East Asia, and as a contrast the whole changes responding to the SST pattern change are not obvious. We can see that the SAT changes in responses to the uniform SST warming show the maximum value for every subregion over East Asia, and the average increase is about $7^{\circ} \mathrm{C}$.

\section{Changes of EAWM in response to different forcings}

Prediction and even projection of EAWM is still imperfect due to its complexity. The decomposition framework in this study could induce a better understanding of the EAWM change.

Under the different forcings, the East-Asian SAT changes are likely to be accompanied by changes in the EAWM-associated circulation. Figure $6 \mathrm{a}-\mathrm{c}$ show the lower-troposphere wind changes in response to the uniform SST warming. The anticyclonic circulation anomaly is evident over the eastern 

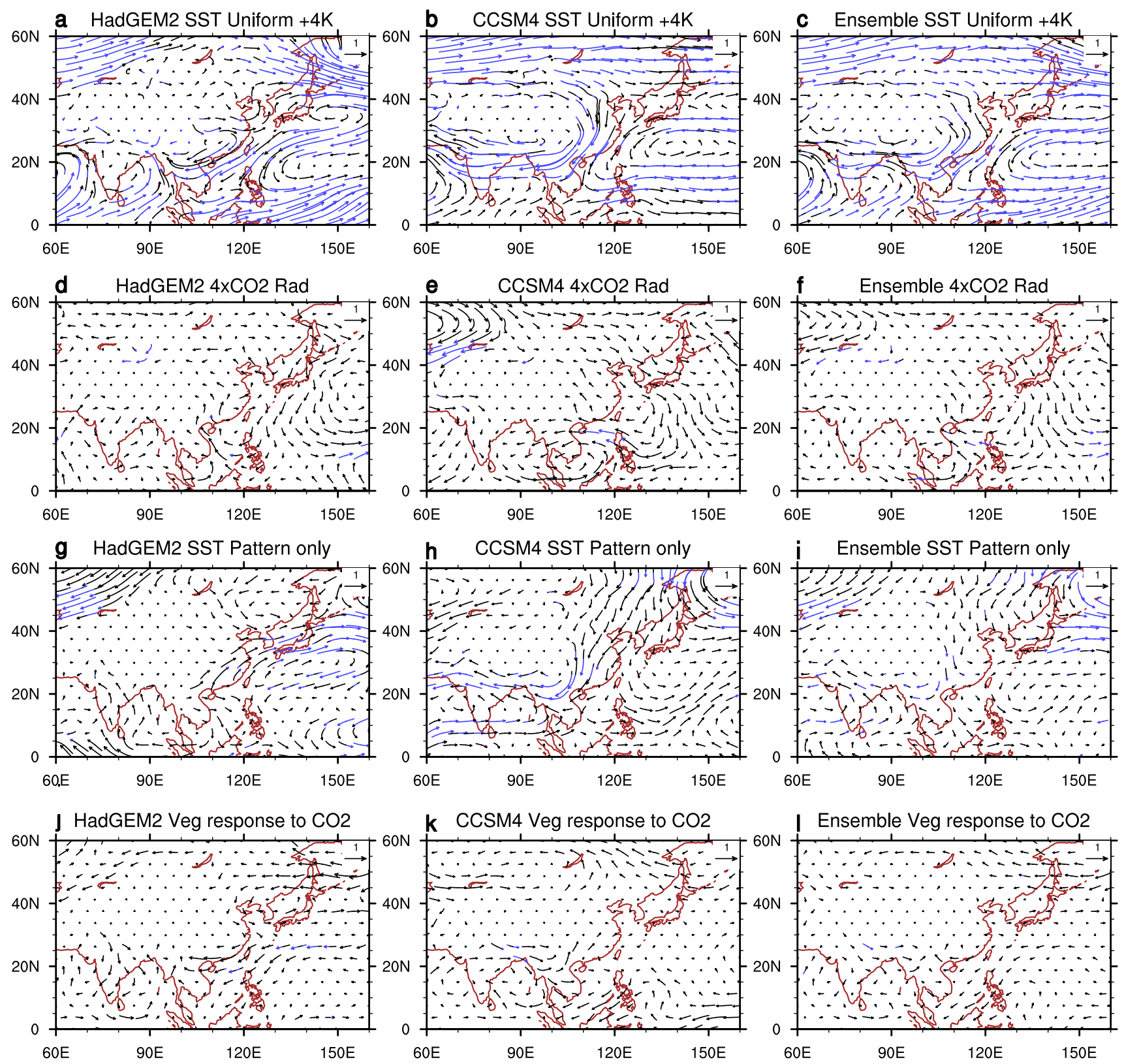

Fig. 6 DJF $850 \mathrm{hPa}$ wind changes $(\mathrm{m} / \mathrm{s})$ in response to the uniform SST Warming $+4 \mathrm{~K}(\mathbf{a}-\mathbf{c}), 4 \times \mathrm{CO}_{2}(\mathbf{d}-\mathbf{f})$, SST pattern change $(\mathbf{g}-\mathbf{i})$, and plant physiological effect $(\mathbf{j}-\mathbf{l})$ for HadGEM2, CCSM4, and the ensemble mean, with the blue vectors exceeding the $95 \%$ confidence level

and southern East Asian continent, which indicates that the uniform SST warming could enhance EAWM. One of the factors contributed to the formation of monsoon is the difference between land surface temperature and SST. In boreal winter, owing to the larger heat capacity for the ocean, the ocean is relatively warmer than most of land regions, and this causes a land-sea thermal contrast, leading to high pressures over land, which is the main cause of the EAWM formation. In response to the uniform SST warming, the increased SST would enhance this thermal contrast and thus the EAWM.
The change of lower tropospheric wind in response to the pure $\mathrm{CO}_{2}$ radiative effect is also examined, as shown in Fig. 6d-f. The simulated change is not remarkable and however, an anticyclonic circulation anomaly is visible in the north of the Philippines. As a result, the $4 \times \mathrm{CO}_{2}$ radiative effect would induce southwesterly wind anomaly on the northwest side of the anomalous anticyclonic circulation over the east coast of China and weaken the EAWM, though not significantly. In response to the uniform SST warming, the whole ocean warms up close to $4 \mathrm{~K}$, while the land surface temperature remains fixed, which could 
initially intensify the land-sea thermal contrast and then reach the equilibrium situation that the $4 \mathrm{~K}$ warmed SST tend to force an updraft over ocean and downdraft over land on a whole. In this case, the increased SAT over land as the figure shows just is the result of the heat transport forced by the $4 \mathrm{~K}$ warmed ocean, and maybe more importantly, the adiabatic heating process also acts to contribute to the more intense warming over land, besides the warming induced by smaller heat capacity and limited moisture availability of land, and this part of analysis will be specifically discussed in Sect. 6.1.

The increased concentration of $\mathrm{CO}_{2}$ leads to an enhanced downwelling longwave radiation, and the more intensified land surface warming could be the result of constant SSTs held in this experiment, causing the decreased land-sea thermal contrast in winter and weakened EAWM as HadGEM2 shows. As for the influence of the SST pattern change, simulations show a difference between the two models, where specifically, the southwesterly flow anomaly appears in the southeast coast of China in HadGEM2, while there is a northeasterly anomaly in CCSM4, resulting in that the ensemble mean is relatively small (Fig. 6g-i). Thus, the SST pattern change seems to be the main source of uncertainty regarding EAWM circulation change across the two models. Finally, the influence of the plant physiological effect on the EAWM is not significant, compared with the uniform SST warming and SST pattern change (Fig. 6j, k).

The vertical structure of meridional wind changes along $110^{\circ} \mathrm{E}$ are shown to clarify the circulation changes relevant to the EAWM. The northerly wind anomaly is remarkable in the southern East Asia for HadGEM2, especially in the lower atmosphere, and much stronger in the most areas of East Asia for CCSM4 (Fig. 7), which is consistent with the conclusion of enhanced EAWM in response to the uniform SST warming as $850 \mathrm{hPa}$ wind changes show. Besides, the large difference is extremely significant in the whole troposphere. The northerly wind seems to be weakened in the lower layer over East Asia for the direct $\mathrm{CO}_{2}$ radiative effect though neither of the two models is statistically significant. The difference between the two models is still large for the SST pattern change. The southerly wind appears to be enhanced on the lower levels in HadGEM2, whereas the northerly wind of the whole troposphere is enhanced in CCSM4. But we can see that the inconsistency is not as remarkable as in the uniform SST warming experiment, which demonstrates that the uniform SST warming is probably the more crucial reason for the uncertainty of the circulation change through the whole troposphere, while the SST pattern change mainly acts to contribute to the inconsistence for the wind change over lower-troposphere, including EAWM. As for the influence of the plant physiological effect, the lower layer shows the weakened northerly wind in the sense of ensemble mean.

The index of EAWM (EAWMI) of Wang (2004) is applied to further analysis, which is defined as the normalized $850 \mathrm{hPa}$ wind velocity, averaged in the area $\left(25^{\circ}-50^{\circ}\right.$ $\left.\mathrm{N}, 115^{\circ}-145^{\circ} \mathrm{E}\right)$. Positive index value indicates a strong EAWM. The ensemble mean result for 30-year averaged winter EAWMI change for uniform SST warming is about 0.604, which further indicates that the EAWM could be enhanced in response to the uniform SST warming. The
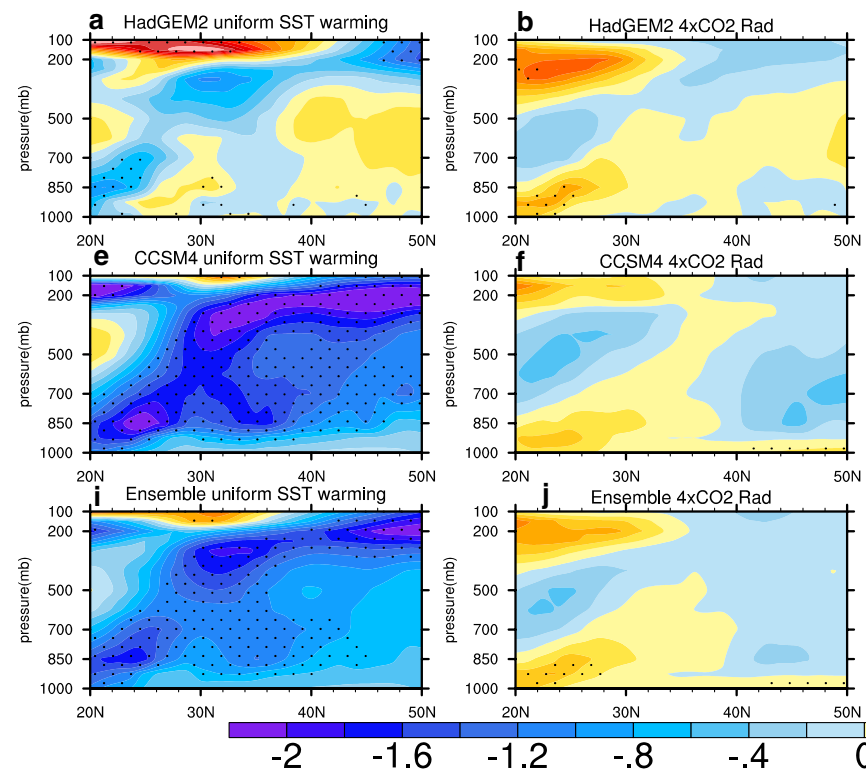
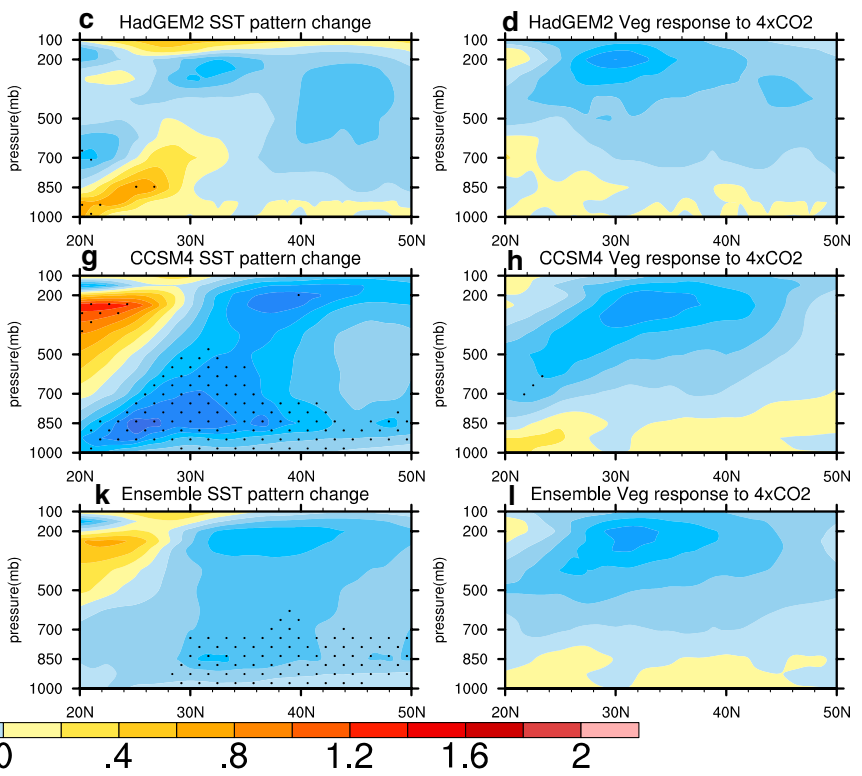

Fig. 7 Vertical structure of meridional wind changes $(\mathrm{m} / \mathrm{s})$ over the area of $20^{\circ}-50^{\circ} \mathrm{N}, 110^{\circ} \mathrm{E}$ in response to the uniform SST Warming $+4 \mathrm{~K}(\mathbf{a}, \mathbf{e}, \mathbf{i}), 4 \times \mathrm{CO}_{2}(\mathbf{b}, \mathbf{f}, \mathbf{j})$, SST pattern change $(\mathbf{c}, \mathbf{g}, \mathbf{k})$, and plant physiological effect $(\mathbf{d}, \mathbf{h}, \mathbf{l})$ for HadGEM2, CCSM4, and the ensemble mean, with stippled areas exceeding the $95 \%$ confidence level 


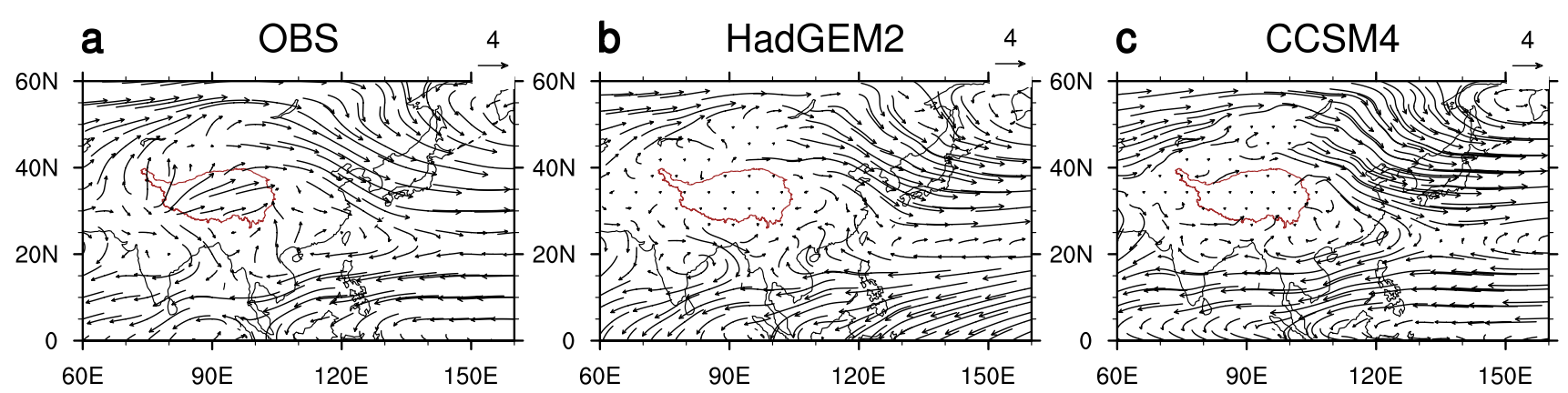

Fig. 8 The averaged winter $850 \mathrm{hPa}$ wind (m/s) in historical experiment for HadGEM2, CCSM4 and observational result during 1948-2004 for NCEP/NCAR reanalysis. The area in the red line represents the Qinghai-Tibetan Plateau

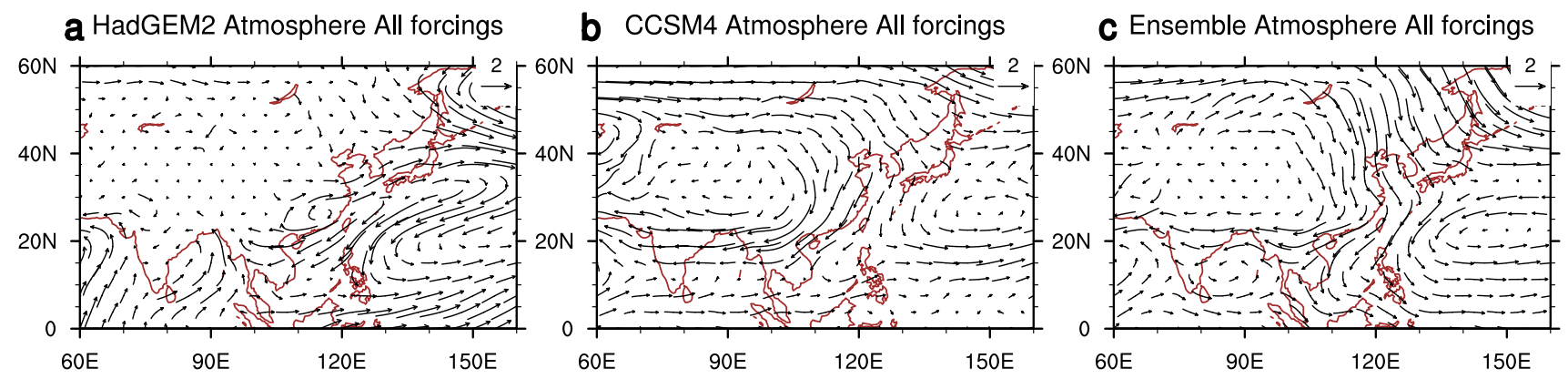

d HadGEM2 Coupled abrupt $4 \times \mathrm{CO} 2$

e CCSM4 Coupled abrupt4xCO2
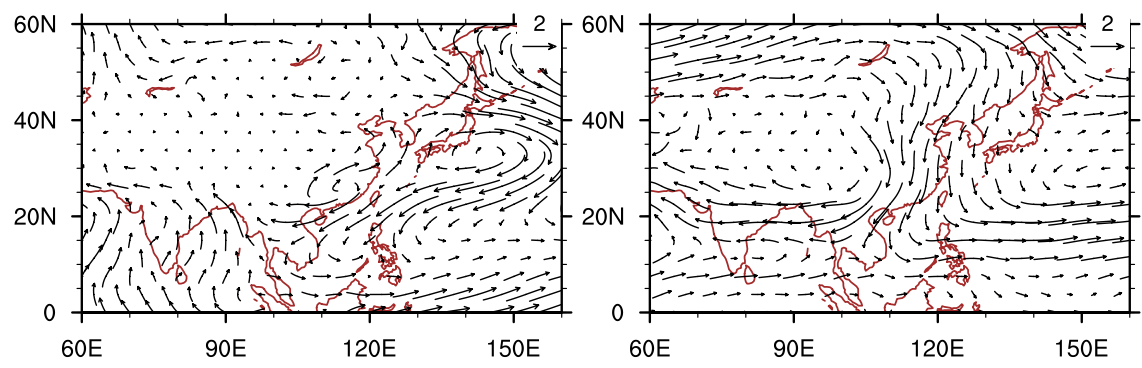

f Ensemble Coupled abrupt $4 \times \mathrm{CO} 2$

$g$ HadGEM2 Coupled-Atmos.

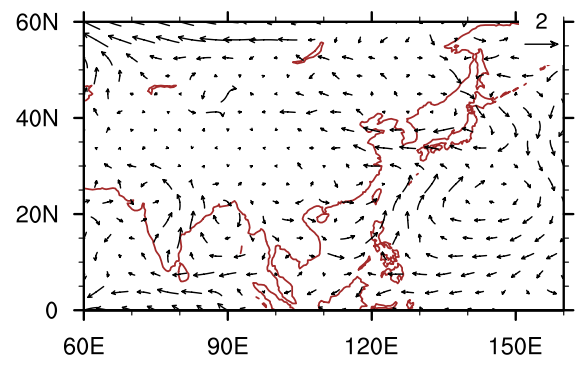

h CCSM4 Coupled-Atmos.
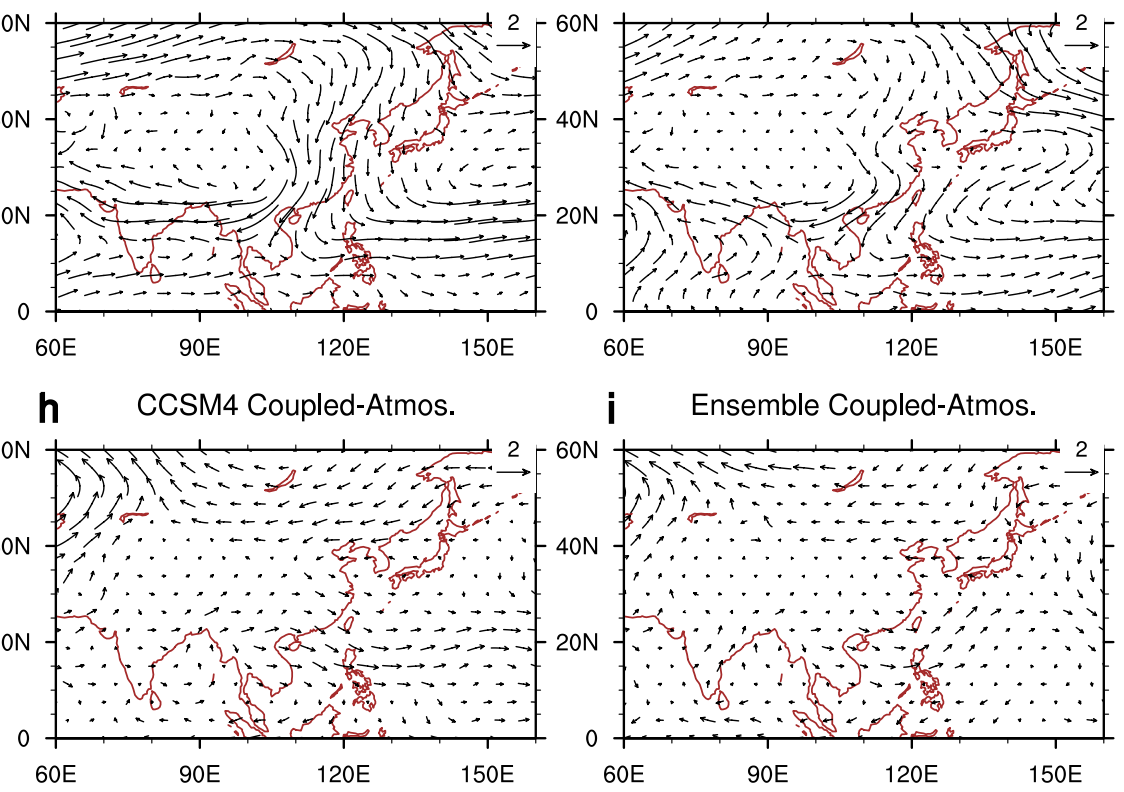

Fig. 9 The sum of all the individual atmosphere-only components for winter $850 \mathrm{hPa}$ wind changes (m/s) over East Asia (a-c), the coupled abrupt $4 \times \mathrm{CO}_{2}$ response $(\mathbf{d}-\mathbf{f})$, and the difference between the coupled model and the sum of components $(\mathbf{g}-\mathbf{i})$

results for the $\mathrm{CO}_{2}$ radiative effect, SST pattern change, and plant physiological effect are $-0.053,0.289$, and -0.067 , respectively. In general, the influences of the uniform SST warming and SST pattern change are likely to enhance the EAWM, while the $\mathrm{CO}_{2}$ radiative effect and plant physiological effect slightly lead to the weakened one.
The comparison of $850 \mathrm{hPa}$ wind between the model simulations and observational result are also taken into account. We can see that the two models can generally capture the characteristics of $850 \mathrm{hPa}$ wind as the observational results show (Fig. 8). 


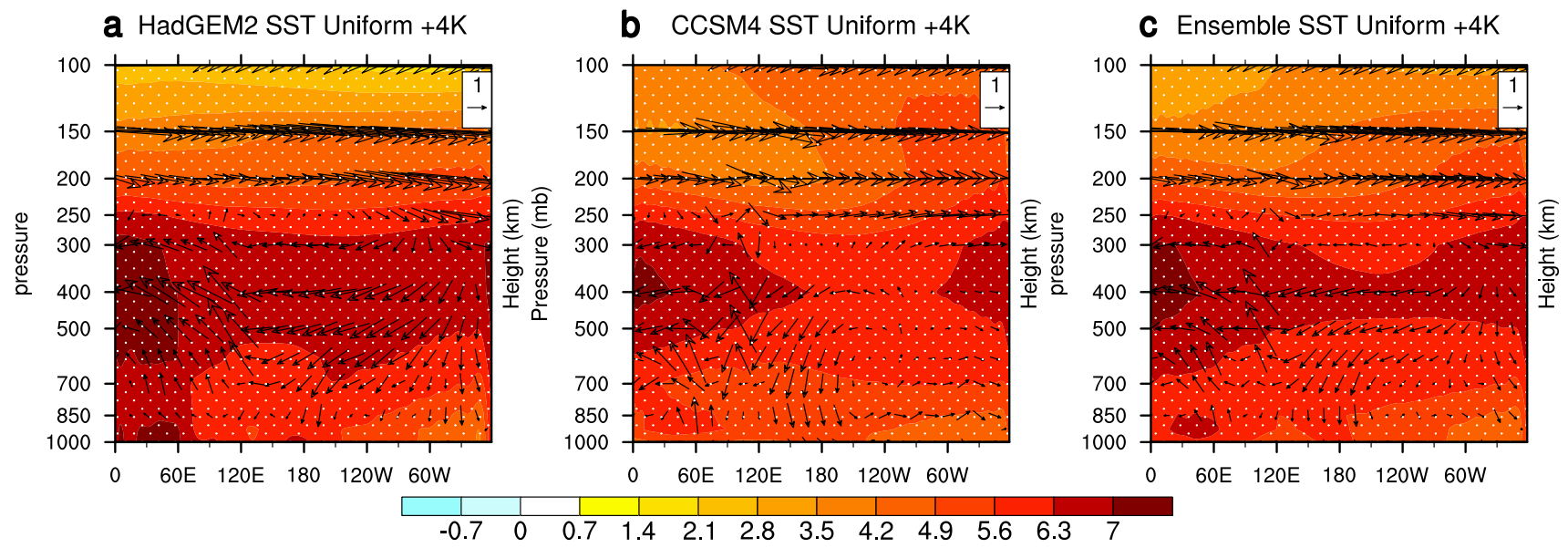

Fig. 10 Vertical distribution for the changes of meridional mean winter air temperature $\left({ }^{\circ} \mathrm{C}\right.$, shading), zonal wind $(\mathrm{m} / \mathrm{s}$, vector), and vertical velocity $\left(\mathrm{m} / \mathrm{s}\right.$, vector) over the region of $15^{\circ}-50^{\circ} \mathrm{N}, 80^{\circ}-150^{\circ} \mathrm{E}$ in response to the uniform SST warming. The air temperature changes at the $95 \%$ confidence level are stippled

transport more energy into mid-high latitudes, resulting in a significant increase of SAT over East Asia.

We can see that the warming over Qinghai-Tibet plateau and northern East Asia is the most dramatic, and the land area seems to undergo the more intense SAT increase than the oceans. Joshi et al. (2007) and Byrne (2013) ever pointed out that large areas of the land surface at most latitudes warms with larger amplitude than those of the surrounding oceans. Their results indicated that associated with local feedbacks and the hydrological cycle over land, the effect of limitation of moisture in the boundary layer over land is to directly enhance land surface warming.

It is also found that circulation change associated with the uniform SST warming could lead to changes in SAT over East Asia. Figure 10 shows the vertical distribution for the changes of the meridional mean winter air temperature, zonal wind, and vertical velocity $\left(15^{\circ}-50^{\circ} \mathrm{N}, 80^{\circ}-150^{\circ} \mathrm{E}\right)$ in response to the uniform SST warming. We can see that the warming center locates around $400 \mathrm{hPa}$ to the east of $105^{\circ} \mathrm{E}$ where the downdraft change is most evident, which could transport energy into the East-Asian land areas from

The ocean will heat up atmosphere intensely when SST uniformly increases by $4 \mathrm{~K}$, especially in tropical areas, and thus

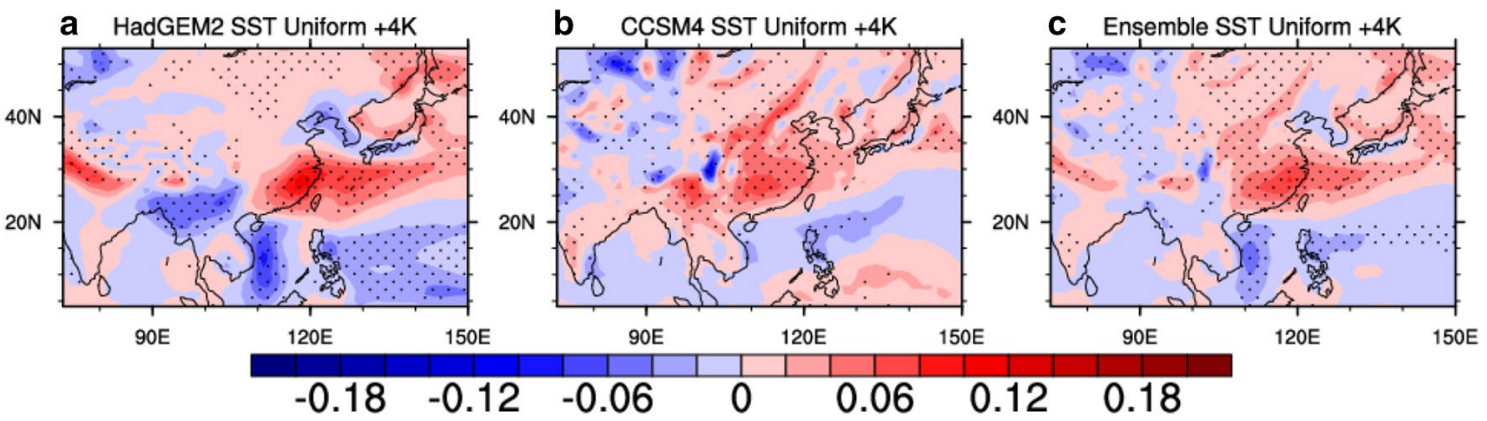

Fig. 11 Integral for adiabatic heating change from 1000 to $500 \mathrm{hPa}(\mathrm{K} / \mathrm{s})$ in the uniform SST warming experiment, with stippled areas exceeding the $95 \%$ confidence level 

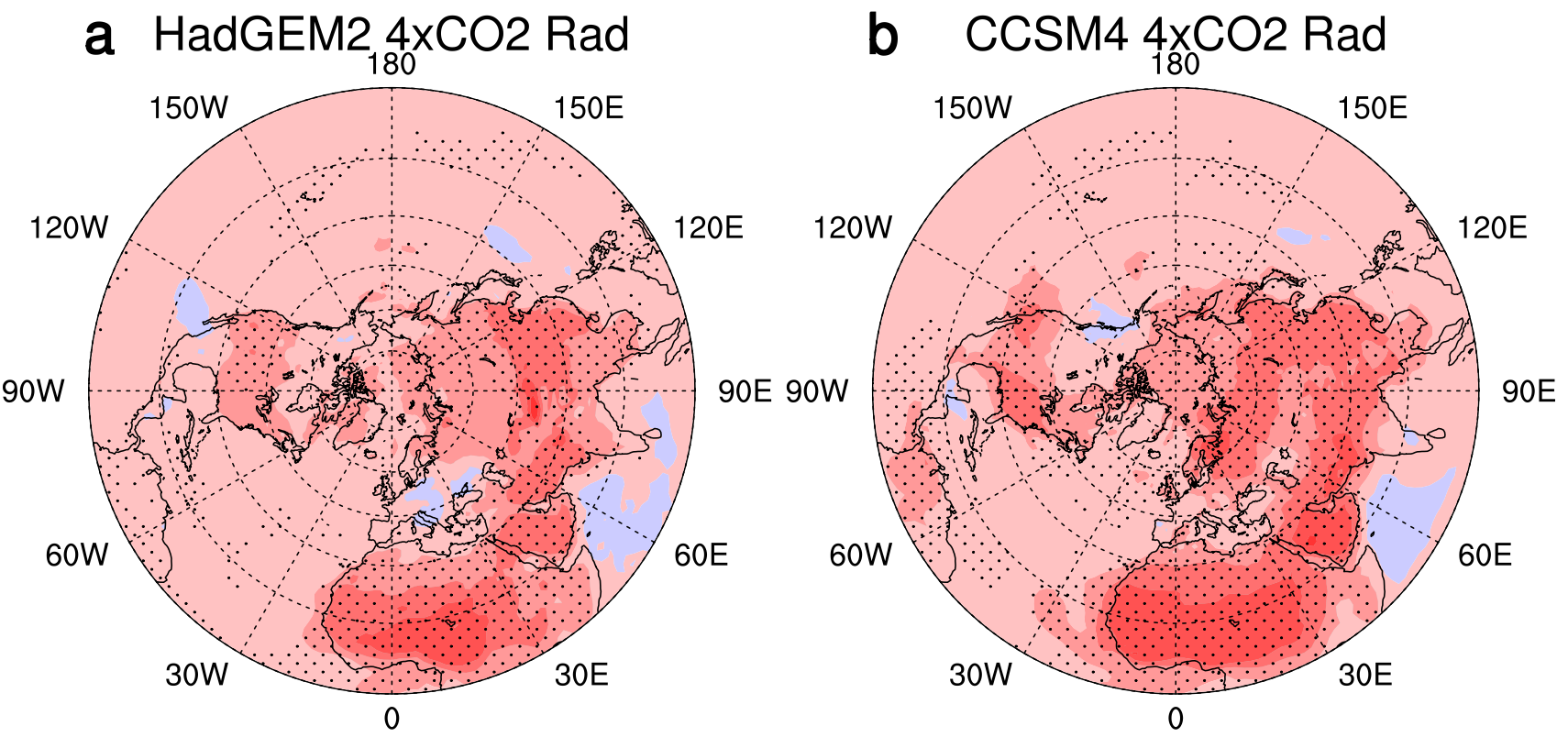

\section{c Ensemble $4 \times \mathrm{xO} 2 \mathrm{Rad}$}

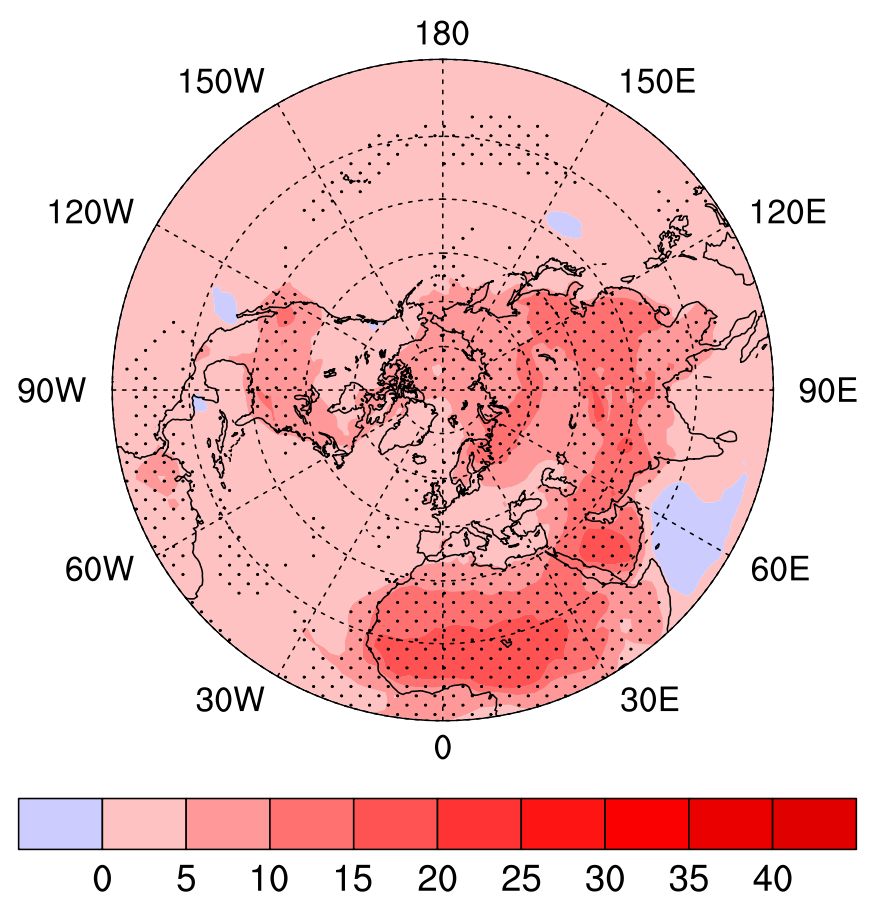

Fig. 12 DJF surface downward longwave radiation changes $\left(\mathrm{W} / \mathrm{m}^{2}\right)$ in response to the $4 \times \mathrm{CO}_{2}$ radiative effect over the northern hemisphere, with stippled areas exceeding the $95 \%$ confidence level

the south/east to north/west and then downward to surface and contribute to the significant SAT increase in land. More importantly, the associated adiabatic subsidence can also contribute to the low-level warming. The effect of uniform SST warming could enhance the updraft in low latitudes and subsidence over East Asia land areas.
In order to see clearly this possible mechanism of the more intensified warming over land, we examine the thermodynamic energy budget, which can be written as

$\partial \mathrm{T} \partial \mathrm{t}+\mathrm{V} \cdot \nabla \mathrm{T}-\omega(\kappa \mathrm{T} / \mathrm{p}-\partial \mathrm{T} / \partial \mathrm{p})=\mathrm{Q} / \mathrm{c}_{\mathrm{p}}$,

where $\partial \mathrm{T} / \partial \mathrm{t}$ represents the temperature tendency, $\mathrm{V} \cdot \nabla \mathrm{T}$ is the horizontal advection of temperature, $\omega(\kappa T / p-\partial T / \partial p)$ is 


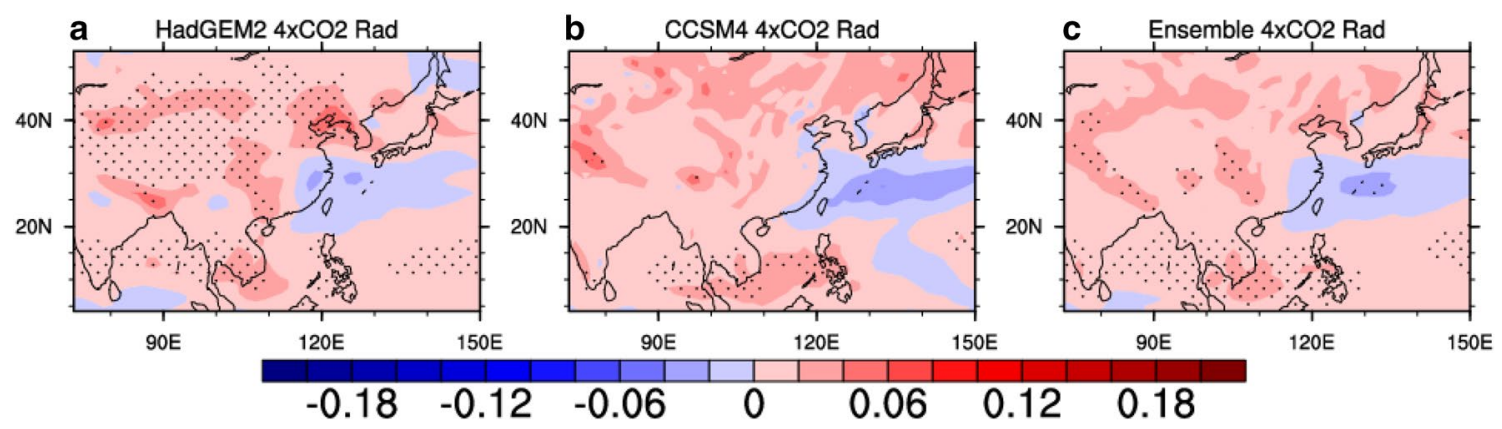

Fig. 13 Integral for diabatic heating change from 1000 to $500 \mathrm{hPa}(\mathrm{K} / \mathrm{s})$ in response to the $4 \times \mathrm{CO}_{2}$ radiative effect, with stippled areas exceeding the $95 \%$ confidence level

the vertical advection of temperature, and $\mathrm{Q} / \mathrm{c}_{\mathrm{p}}$ represents the diabatic heating/cooling. The part of $\omega(\kappa \mathrm{T} / \mathrm{p}-\partial \mathrm{T} / \partial \mathrm{p})$ integral from 1000 to $500 \mathrm{hPa}$ is calculated representing the low layer adiabatic subsidence heating. We can see that the adiabatic heating induced by the downdraft intensifies in most land areas, especially over East China (Fig. 11), and clearly, the low-level warming could result from the downdraft above land region driven by the uniform SST warming to $4 \mathrm{~K}$, through an adiabatic process. This mechanism is different from the diabatic heating connected with the EAWM change in terms of the land-ocean thermal contrast. In other words, although the land warms more significantly than the ocean, it is SST-warming forced circulation changes, including the EAWM change.

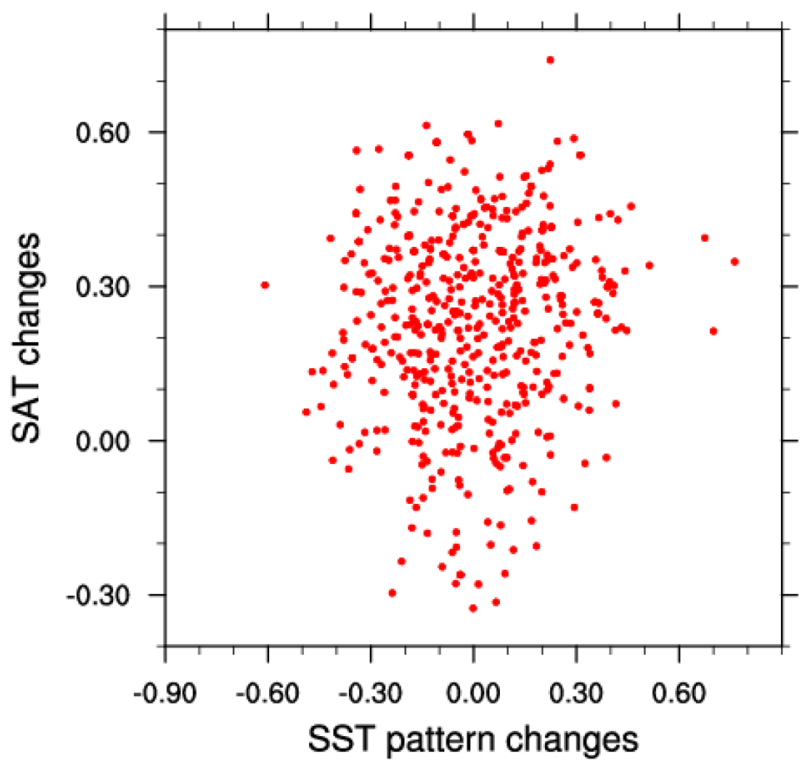

Fig. 14 The correlation coefficients for the winter SST pattern changes (horizontal axis) between any two model results for RCP8.5 experiments from CMIP5 and for winter SAT changes over East Asia (vertical axis)

\subsection{Response to the direct $\mathrm{CO}_{2}$ effect}

$\mathrm{CO}_{2}$, as a major greenhouse gas, can absorb long-wave radiation and lead to the greenhouse effect. This leads to land surface warming even in the absence of SST warming, and such a component of land warming is referred to as the direct $\mathrm{CO}_{2}$ effect. Figure 12 shows that the surface downward longwave radiation flux increases in most of the northern hemisphere, especially over land regions, inducing SAT increase over East Asia. Similarly, the diabatic heating change is also estimated. Figure 13 shows the integral for lower-tropospheric diabatic heating change in the $4 \times \mathrm{CO}_{2}$ direct radiative effect experiment. We can see that the diabatic heating is enhanced over the most areas of East Asia, which further explains that the increased SAT is induced by the diabatic heating from the greenhouse effect of the $\mathrm{CO}_{2}$.

\subsection{Response to the SST pattern change}

The simulations for the SST pattern change show big differences in the south and east of East Asia, with a more significantly decreased SAT for CCSM4 (Fig. 2). As known in Sect. 5, the southwesterly flow anomaly appears in the southeast coast of China in HadGEM2, though not so significant, while a stronger northeasterly anomaly occurs in CCSM4 (Fig. 6), which could lead to the decreased SAT, but the similar change in HadGEM2 is not evident. For the lowlevel wind changes, the result of HadGEM2 in the east and south of China is almost reverse to that of CCSM4; that is, the difference between the models is large for their response to the SST pattern change.

Since there are only two models used in this study, in order to figure out the impact of SST pattern change on the inter-model uncertainties for those SAT changes, we here applied a set of RCP8.5 experiments from the CMIP5 (Table 2) to further analysis. The vertical and horizontal axes in Fig. 14 stand for correlation coefficients for the SST pattern changes between any two model results and for SAT 
Fig. 15 DJF SLP changes (hPa) in response to the SST pattern change over the northern hemisphere, with stippled areas exceeding the $95 \%$ confidence level

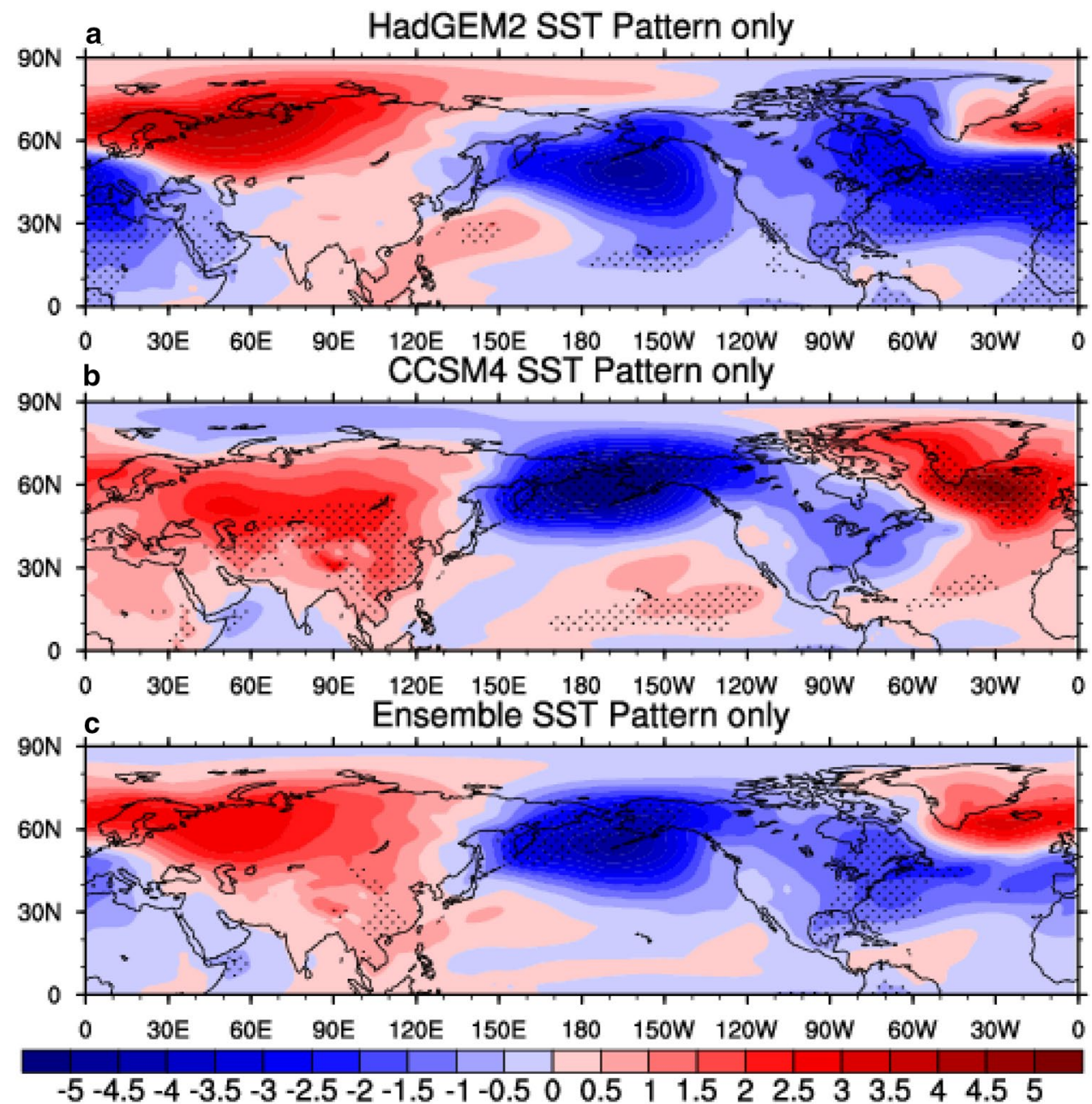

changes over East Asia. It can be clearly seen that the relationships between the East-Asian SAT changes and the SST pattern changes are unclear across models. Particularly, the similar SST pattern change may induce the totally different SAT changes in East Asia, and on the other hand, the similar SAT changes could result from the different kinds of SST pattern changes. The differences could be generated by some distinct physical processes in these models, which still remains unclear and needs to be further studied. We further analyzed the changes of winter SLP (Fig. 15) in response to SST pattern change over the northern hemisphere. It can be seen that the results show the discrepancy for the distribution of high and low pressure between the two models over the south of East Asia. Since the East-Asian climate is strongly controlled by Siberian high in winter, the inconsistent distribution of high pressure could lead to the different path ways of cold surge as shown in Fig. 16, and the winter SAT change uncertainty in the two models.

\subsection{Response to the plant physiological effect}

Besides its radiative effects, $\mathrm{CO}_{2}$ also has an impact on the physiological processes of vegetation. Climate changes, including global warming have large influences on terrestrial biosphere. Global vegetation tends to become denser under future global warming, and the species of vegetation could also be influenced. Vegetation has proved to be one of the important roles for climate change and shows the significant influence on surface temperature change under global warming for regional areas. The changes of vegetation may lead to warming in the future (Ryouta and Abe-Ouchi 2009; Jiang et al. 2011). The annual surface temperature proved to increase over most land parts of Eurasia, which could be induced by the different surface albedos resulting from vegetation changes (Jiang et al. 2011). The opening of stomates can increase evapotranspiration intensity and relative water loss rate, however, the increase of $\mathrm{CO}_{2}$ can also have an impact on vegetation by narrowing plant stoma (Field and Mooney 1995). The suppression of the evapotranspiration rate over land is unfavorable for the evaporative cooling and 

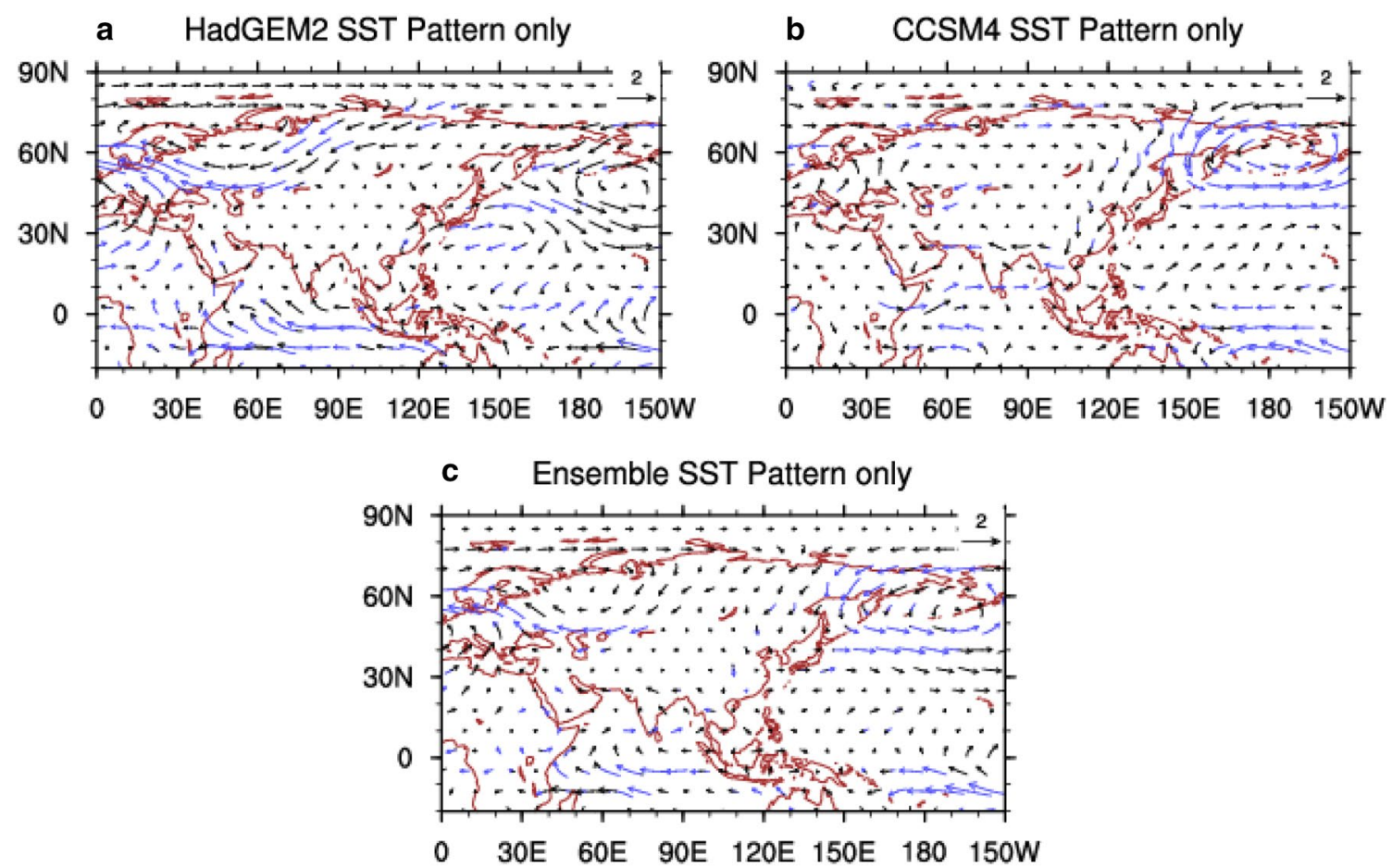

Fig. 16 Winter $850 \mathrm{hPa}$ wind changes $\left(\mathrm{m} / \mathrm{s}^{2}\right)$ in response to the SST pattern change, with the blue vectors exceeding the $95 \%$ confidence level

Table 2 Summary of models using from CMIP5

\begin{tabular}{llll}
\hline Model & Institute & Model & Institute \\
\hline ACCESS1-0 & CSIRO, BOM/Australia & GFDL-ESM2M & NOAA-GFDL/USA \\
ACCESS1-3 & CSIRO, BOM/Australia & GISS-E2-H & NASA-GISS/USA \\
BCC-CSM1-1 & BCC/China & GISS-E2-R & NASA-GISS/USA \\
BCC-CSM1-1-M & BCC/China & HadGEM2-CC & NOCH/UK \\
CanESM2 & CCCma/Canada & HadGEM2-ES & NOCH/UK \\
CCSM4 & NCARNSF-DOE-NCAR/USA & INM-CM4 & INM/Russia \\
CESM1-BGC & NCARNSF-DOE-NCAR/USA & IPSL-CM5A-LR & IPSL/France \\
CESM1-CAM5 & NCARNSF-DOE-NCAR/USA & IPSL-CM5A-MR & IPSL/France \\
CMCC-CM & CMCC/Italy & IPSL-CM5B-LR & IPSL/France \\
CMCC-CMS & CMCC/Italy & MIROC5 & MIROC/Japan \\
CNRM-CM5 & CNRM-CERFACS/France & MPI-ESM-LR & MPI-M/Germany \\
CSIRO-Mk3-6-0 & CSIRO-QCCCE/Australia & MPI-ESM-MR & MPI-M/Germany \\
EC-EARTH & ICHEC/Netherlands/Ireland & MRI-CGCM3 & MRI/Japan \\
FIO-ESM & FIO/China & NorESM1-M & NCC/Norway \\
GFDL-CM3 & NOAA-GFDL/USA & NorESM1-ME & NCC/Norway \\
GFDL-ESM2G & NOAA-GFDL/USA & & \\
\hline
\end{tabular}

increases the SAT over land regions (Boucher et al. 2009; Chadwick et al. 2017). On the other hand, it has been proved that the increased $\mathrm{CO}_{2}$ concentration could reduce vegetation transpiration, and the soil retains more water (Bounoua et al. 1999; Boucher et al. 2009; Wigley and Jones 1985; Sellers et al. 1996). In CFMIP, the modeling groups turn off the terrestrial carbon cycle, as well as the dynamic vegetation, so the distribution and species of the terrestrial vegetation won't change when the $\mathrm{CO}_{2}$ concentration rises. In this study, only the influence of plant physiological effect is taken into account.

To indicate this, Fig. 17 shows DJF surface sensible heating change in response to the plant physiological effect, which shows that sensible heat flux increases over southern East Asia, particularly in the Indo-China Peninsula, where 


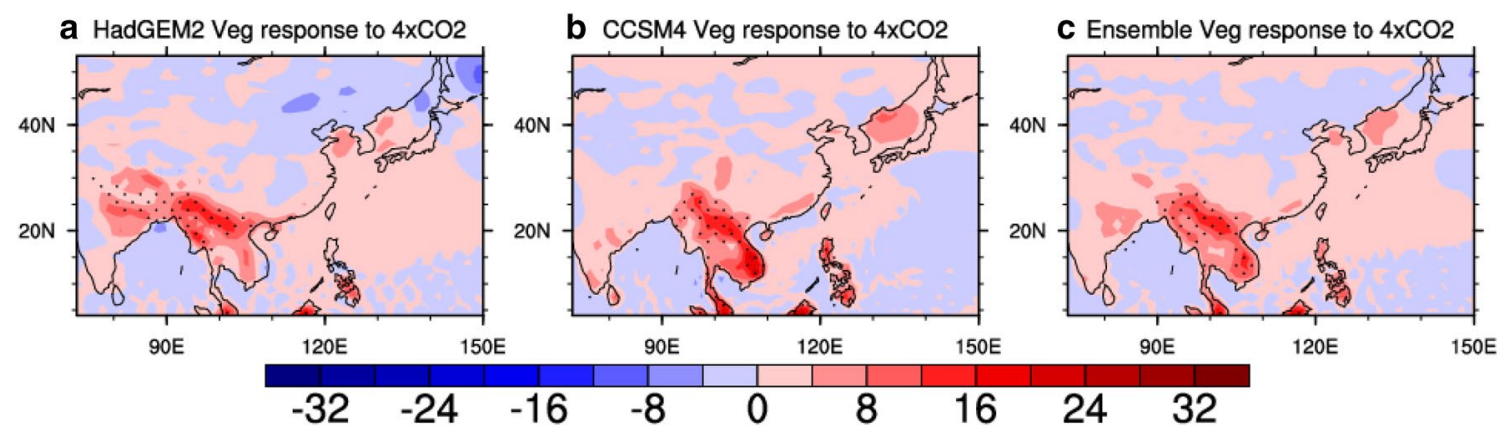

Fig. 17 DJF sensible heat changes $\left(\mathrm{W} / \mathrm{m}^{2}\right)$ in response to the plant physiological effect, with stippled areas exceeding the $95 \%$ confidence level

more warming of the land surface is located over highly vegetated regions.

\section{Summary and discussions}

It is a hot issue how to quantify the changes of the EastAsian SAT under different forcings. In this study, based on a set of atmosphere-only timeslice experiments, the winter SAT and its associated monsoonal circulation changes in East Asia have been examined by employing the decomposition framework that was designed by Chadwick et al. (2017) to examining tropical rainfall changes. The winter East-Asian SAT changes in response to the uniform SST warming, $4 \times \mathrm{CO}_{2}$, SST pattern changes, and plant physiological effect have been diagnosed and compared to each other to better understand the key feature of the winter SAT changes over East Asia and their possible mechanisms.

Features of the SAT responses vary with regions and forcings. The SAT change in response to the uniform SST warming shows a non-uniform and large increase over East Asia, especially in the Qinghai-Tibetan Plateau and northern East Asia. The result also shows the increased SAT change over East Asia in the $4 \times \mathrm{CO}_{2}$ direct radiative effect experiment, but with magnitude much smaller than that responding to the uniform SST warming, where land warms more intensely than ocean. As for the influence of the plant physiological effect, SAT increases in most land regions, particularly in the southern East Asia which is highly vegetated, compared to other regions. For the distinct sub-regions, the uniform SST warming and $\mathrm{CO}_{2}$ radiative effect both appear to induce more intense SAT increase over northern East Asia, especially in NW, while the plant physiological effect has a more significant influence on the southwestern/southern of East Asia. It is also found that the SST pattern change appears to be a main source for inter-model uncertainty for SAT projection over East Asia in winter due to the diverse results between the two models used here.
Analysis of monsoonal circulation changes showed that the uniform SST warming could enhance EAWM, which could be the result of the intensified SST warming to $4 \mathrm{~K}$. The simulation results of EAWM change in response to 4 $\times \mathrm{CO}_{2}$, including radiative effect and plant physiological effect, are not large, but an anticyclonic circulation anomaly appears in the north of the Philippines in response to $4 \times$ $\mathrm{CO}_{2}$ direct radiative effect, which indicates that the $4 \times \mathrm{CO}_{2}$ direct radiative effect could slightly weaken the EAWM. As for the effect of SST pattern change, the inter-model uncertainty is large.

To understand the possible mechanisms of the SAT changes for different forcings, our results demonstrated that ocean could heat up the atmosphere intensely when SST uniformly rises by $4 \mathrm{~K}$ and in addition, the increased moisture owning to the enhanced evaporation will lead to a further SAT rising via the water vapor feedback, and the adiabatic heating process can also contribute to the more intense warming over land. As a major greenhouse gas, $\mathrm{CO}_{2}$ can absorb long-wave radiation and then lead to the SAT rising. Besides the radiative effect, increased $\mathrm{CO}_{2}$ could narrow plant stomatal and lead to reduced transpiration, leading to the higher SAT change, and we found that the surface sensible heat increases over southern East Asia, particularly in Indo-China Peninsula, where SAT rises most remarkably in these regions.

Since this is a set of atmosphere-only experiments, the lack of atmosphere-ocean coupling process could lead to biases compared with coupled simulations. Here we further compared the winter SAT change responses between timeslice experiments and coupled model. The response of the former can be estimated by taking difference between piSSTTot and piSST, and that of the latter can be done by subtracting piControl from abrupt $4 \times \mathrm{CO}_{2}$. In general, the spatial pattern correlations between the coupled and timeslice results exceed the $95 \%$ confidence level and their differences are quite small in the two models (as Fig. 3 shows). This residual result, the difference between coupled runs and this set of atmosphere-only experiments 
demonstrates that this set of atmosphere-only experiments can well capture the responses in coupled models.

Finally, the uncertainty in temperature change due to the uncertainty in the climate sensitivity as simulated by coupled models should also be taken into consideration. In broad terms, the climate sensitivity is defined as the global mean SAT change in response to the $2 \times \mathrm{CO}_{2}$ compared with the pre-industrial level. Previous studies pointed out that the increased global mean SAT is about $3 \mathrm{~K}$ in the equilibrium state, and the equilibrium surface warming due to doubled $\mathrm{CO}_{2}$ will be in the range of $1.5-4.5^{\circ} \mathrm{C}$, with the most probable value near $3{ }^{\circ} \mathrm{C}$ (IPCC 2018). Here, we estimated the SAT increase based on piControl and abrupt $4 \times \mathrm{CO}_{2}$ experiments in these two models, and the results show that the global mean SAT changes range from 5.51 to $8.04{ }^{\circ} \mathrm{C}$ in two models. As for the East-Asian region, the SAT changes range from 4.27 to $6.62{ }^{\circ} \mathrm{C}$ for the two models. The change of SAT due to the increased concentration of $\mathrm{CO}_{2}$ is a result of various feedback progresses. Particularly, the cloud feedback can lead to a large amount of temperature uncertainty, or uncertainty in the climate sensitivity (Zhou and Chen 2015). This makes the estimation of SAT change more complicated and uncertain.

Acknowledgements We sincerely thank the researchers working on data outputs from the CFMIP-3, for their excellent works on each experiment are the fundamental step to carry out this research. The study is jointly sponsored by the National Key Research and Development Program on Monitoring, Early Warning and Prevention of Major Natural Disaster (2018YFC1506004, 2017YFC1502302), and the UK-China Research and Innovation Partnership Fund through the Met Office Climate Science for Service Partnership (CSSP) China as part of the Newton Fund.

Open Access This article is licensed under a Creative Commons Attribution 4.0 International License, which permits use, sharing, adaptation, distribution and reproduction in any medium or format, as long as you give appropriate credit to the original author(s) and the source, provide a link to the Creative Commons licence, and indicate if changes were made. The images or other third party material in this article are included in the article's Creative Commons licence, unless indicated otherwise in a credit line to the material. If material is not included in the article's Creative Commons licence and your intended use is not permitted by statutory regulation or exceeds the permitted use, you will need to obtain permission directly from the copyright holder. To view a copy of this licence, visit http://creativecommons.org/licenses/by/4.0/.

\section{References}

Berg A, Findell K, Lintner B, Giannini A, Seneviratne SI, Bart VDH, Lorenz R, Pitman A, Hagemann S, Meier A, Cheruy F, Ducharne A, Malyshev S, Milly PCD (2016) Land-atmosphere feedbacks amplify aridity increase over land under global warming. Nat Clim Change 6(9):869-874. https://doi.org/10.1038/nclimate3029

Bernstein L, Bosch P, Canziani O, Chen Z, Christ R, Riahi K (2008) IPCC, 2007: Climate change 2007: Synthesis report. IPCC, Geneva. ISBN 2-9169-122-4
Betts RA, Boucher O, Collins M, Cox PM, Falloon PD, Gedney N, Hemming DL, Huntingford C, Jones CD, Sexton DM, Webb MJ (2007) Projected increase in continental runoff due to plant responses to increasing carbon dioxide. Nature 448(7157):10371041. https://doi.org/10.1038/nature06045

Boucher O, Jones A, Betts RA (2009) Climate response to the physiological impact of carbon dioxide on plants in the Met Office unified model HadCM3. Clim Dyn 32(2-3):237-249. https://doi. org/10.1007/s00382-008-0459-6

Bounoua L, Collatz GJ, Sellers PJ, Randall DA, Dazlich DA, Los SO, Berry JA, Fung I, Tucker CJ, Field CB, Jensen TG (1999) Interactions between vegetation and climate: radiative and physiological effects of doubled atmospheric $\mathrm{CO}_{2}$ J Clim 12(2):309-324. https ://doi.org/10.1175/1520-0442(1999)012<0309:ibvacr>2.0.co;2

Byrne MP, O'Gorman PA (2013) Land-ocean warming contrast over a wide range of climates: convective quasi-equilibrium theory and idealized simulations. J Clim 26(12):4000-4016. https:// doi.org/10.1175/JCLI-D-12-00262.1

Cattiaux J, Cassou C (2013) Opposite CMIP3/CMIP5 trends in the winter time Northern Annular Mode explained by combined local sea ice and remote tropical influences. Geophys Res Lett 40:3682-3687. https://doi.org/10.1002/grl.50643

Chadwick R (2015) Which aspects of $\mathrm{CO}_{2}$ forcing and SST warming cause most uncertainty in projections of tropical rainfall change over land and ocean? J Clim 29(7):2493. https://doi. org/10.1175/JCLI-D-15-0777.1

Chadwick R, Douville H, Skinner CB (2017) Timeslice experiments for understanding regional climate projections: applications to the tropical hydrological cycle and European winter circulation. Clim Dyn 49(9-10):3011-3029. https://doi.org/10.1007/s0038 2-016-3488-6

Chen W, Gu L, Wei K, Huang RH (2008) Studies of the dynamic processes of East Asian monsoon system and the quasi-stationary planetary wave activities. Chin J Atmos Sci 32(4):950-966. https ://doi.org/10.3724/SP.J.1148.2008.00288

Chen W, Wei K, Wang L, Zhou Q (2013) Climate variability and mechanisms of the East Asian winter monsoon and the impact from the stratosphere. Chin J Atmos Sci 37(2):425-438. https:// doi.org/10.3878/j.issn.1006-9895.2012.12309

Dao SY, Chen LS (1957) The structure of general circulation over continent of Aisa in summer. Acta Meteorol Sin 28(3):239-247

Ding Y, Liu Y, Liang S, Ma X, Zhang Y, Si D, Liang P, Song Y, Zhang J (2014) Interdecadal variability of the East Asian winter monsoon and its possible links to global climate change. J Meteorol Res 28(5):693-713. https://doi.org/10.1007/s1335 1-014-4046-y

Dong B, Gregory JM, Sutton RT (2009) Understanding land-sea warming contrast in response to increasing greenhouse gases. Part I: transient adjustment. J Clim 22(11):3079-3097. https:// doi.org/10.1175/2009jcli2652.1

Fang JY, Zhu JL, Wang SP, Yue C, Shen HH (2011) Global warming, human-induced carbon emissions, and their uncertainties. Sci China Earth Sci 54:1458-1468. https://doi.org/10.1007/s1143 0-011-4292-0

Field CB, Jackson RB, Mooney HA (1995) Stomatal responses to increased $\mathrm{CO}_{2}$ : implications from the plant to the global scale. Plant Cell Environ 18(10):1214-1225. https://doi. org/10.1111/j.1365-3040.1995.tb00630.x

Gao DM, Li YQ, Jiang XW, Li J, Wu Y (2016) Influence of planetary boundary layer parameterization schemes on prediction of rainfall with different magnitudes in the sichuan basin using the WRF model. Chin J Atmos Sci 40(2):371-389. https://doi. org/10.3878/j.issn.1006-9895.1503.14323

Gong DY, Wang SW (2003) Influence of Arctic oscillation on winter climate over China. J Geogr Sin 13(2):208-216. https://doi. org/10.1007/bf02837460 
Guoyu R (2008) History, current state and uncertainty of studies of climate change attribution. Adv Earth Sci 23(10):1084-1091. https://doi.org/10.3724/SP.J.1005.2008.00543

Hadley G (1735) Concerning the cause of the general trade-winds. Philos Trans 29:58-62. https://doi.org/10.1098/rstl.1735.0014

Halley E (1686) An historical account of the trade winds and the monsoons, observable in the seas between and near the tropics, with an attempt to assign the physical cause of the said winds. Philos Trans R Soc Lond 16:153-168. https://doi.org/10.1098/ rstl.1686.0026

Hsu HH, Chen YL, Kau WS (2001) Effects of atmosphere-ocean interaction on the interannual variability of winter temperature in Taiwan and East Asia. Clim Dyn 17(4):305-316. https://doi. org/10.1007/s003820000116

Huang Y, Ren H-L, Chadwick R, Cheng ZG, Chen QL (2018) Diagnosing changes of winter NAO in response to different climate forcings in a set of atmosphere-only timeslice experiments. Atmosphere 9(1):10. doi:https://doi.org/10.3390/atmos9010010

IPCC (2018) Global warming of $1.5^{\circ} \mathrm{C}$ : impacts of $1.5^{\circ} \mathrm{C}$ of global warming on natural and human systems. Spec Rep 1:177-240

Jeong JH, Lee H, Yoo JH, Kwon MH, Yeh SW, Kug JS, Lee JY, Kim BM, Lee H, Lee WS, Yoon JH, Kim HK (2017) The status and prospect of seasonal climate prediction of climate over Korea and East Asia: a review. Asia Pac J Atmos Sci 53(1):149-173. https://doi.org/10.1007/s13143-017-0008-5

Jhun JG, Lee EJ (2004) A new East Asian winter monsoon index and associated characteristics of the winter monsoon. J Clim 17(4):711-726. https://doi.org/10.1175/15200442(2004)017<0711:ANEAWM > 2.0.CO;2

Jiang DB, Wang HJ, Lang XM (2004) East Asian climate change trend under global warming background. Chin J Geophys 47(4):590-596. https://doi.org/10.1002/cjg2.3536 (in Chinese)

Jiang DB, Zhang Y, Lang X (2011) Vegetation feedback under future global warming. Theor Appl Climatol 106(1-2):211-227. https ://doi.org/10.1007/s00704-011-0428-6

Jiang DB, Tian ZP, Lang XM (2016) Reliability of climate models for China through the IPCC third to fifth assessment reports. Int J Climatol 36:1114-1133. https://doi.org/10.1002/joc.4406

Joshi MM, Gregory JM, Webb MJ, Sexton DMH, Johns TC (2008) Mechanisms for the land/sea warming contrast exhibited by simulations of climate change. Clim Dyn 30(5):455-465. doi:https ://doi.org/10.1007/s00382-007-0306-1

Lang XM, Sui Y (2013) Changes in mean and extreme climates over China with a $2{ }^{\circ} \mathrm{C}$ global warming. Chin Sci Bull 58:14531460. https://doi.org/10.1007/s11434-012-5520-5

Lee MH, Ho CH, Kim J, Song CK (2012) Assessment of the changes in extreme vulnerability over East Asia due to global warming. Clim Change 113(2):301-321. https://doi.org/10.1007/s1058 4-011-0345-9

Lee DK, Cha DH, Jin CS, Choi SJ (2013) A regional climate change simulation over East Asia. Asia Pac J Atmos Sci 49(5):655-664. https://doi.org/10.1007/s13143-013-0058-2

Lee JW, Hong SY, Chang EC, Myoung SS, Kang HS (2014) Assessment of future climate change over East Asia due to the RCP scenarios downscaled by GRIMs-RMP. Clim Dyn 42(3-4):733747. https://doi.org/10.1007/s00382-013-1841-6

Luo X, Wang B (2017) How predictable is the winter extremely cold days over temperate East Asia? Clim Dyn 48(7-8):2557-2568. https://doi.org/10.1007/s00382-016-3222-4

National Report Committee (2007) China's National Assessment Report on climate change. Science Press, Beijing, p 148 (in Chinese)

Park TW, Jeong JH, Ho CH, Kim SJ (2008) Characteristics of atmospheric circulation associated with cold surge occurrences in East Asia: a case study during 2005/2006 winter. Adv Atmos Sci 25(5):791-804. https://doi.org/10.1007/s00376-008-0791-0
Park HJ, Ahn JB (2016) Combined effect of the Arctic Oscillation and the Western Pacific pattern on East Asia winter temperature. Clim Dyn 46:3205-3221. https://doi.org/10.1007/s0038 2-015-2763-2

Park C, Min SK, Lee D, Cha DH, Suh MS, Kang HS, Hong SY, Lee DK, Jeong H, Kyung B, Boo O, Kwon WT (2016) Evaluation of multiple regional climate models for summer climate extremes over East asia. Clim Dyn 46(7):1-18. https://doi.org/10.1007/ s00382-015-2713-z

Rangwala I, Miller JR, Russell GL, Xu M (2010) Using a global climate model to evaluate the influences of water vapor, snow cover and atmospheric aerosol on warming in the Tibetan Plateau during the twenty-first century. Clim Dyn 34(6):859-872. https://doi. org/10.1007/s00382-009-0564-1

Ryouta O, Abe-Ouchi A (2009) Influence of dynamic vegetation on climate change arising from increasing $\mathrm{CO}_{2}$. Clim Dyn 33(5):645663. https://doi.org/10.1007/s00382-009-0611-y

Sellers PJ, Bounoua L, Collatz GJ, Randall DA, Dazlich DA, Los SO, Berry JA, Fung I, Tucker CJ, Field CB, Jensen TG (1996) Comparison of radiative and physiological effects of doubled atmospheric $\mathrm{CO}_{2}$ on climate. Science 271(5254):1402-1406. https:// doi.org/10.1126/science.271.5254.1402

Seo YW, Kim H, Yun KS, Lee JY, Ha KJ, Moon JY (2014) Future change of extreme temperature climate indices over East Asia with uncertainties estimation in the CMIP5. Asia Pac J Atmos Sci 50(1 Supplement):609-624. https://doi.org/10.1007/s1314 3-014-0050-5

Tan B, Chen W (2014) Progress in the study of the dynamics of extratropical atmospheric teleconnection patterns and their impacts on East Asian climate. J Meteorol Res 28(5):780-802. https://doi. org/10.1007/s13351-014-4041-3

Wang HJ (2004) A new East Asian winter monsoon intensity index and atmospheric circulation comparison between strong and weak composite. Quat Sci 24(1):19-27. https://doi. org/10.1117/12.528072

Webb MJ, Lambert FH, Gregory JM (2013) Origins of differences in climate sensitivity, forcing and feedback in climate models. Clim Dyn 40(3-4):677-707. https://doi.org/10.1007/s0038 2-012-1336-x

Wei K, Bao Q (2012) Projections of the East Asian winter monsoon under the IPCC AR5 scenarios using a coupled model: IAP_FGOALS. Adv Atmos Sci 29(6):1200-1214. https://doi. org/10.1007/s00376-012-1226-5

Wigley TML, Jones PD (1985) Influences of precipitation changes and direct $\mathrm{CO}_{2}$ effects on streamflow. Nature 314:149-152

Xiao X, Wen C, Guangzhou F, Dingwen Z (2016) Possible external forcing factors for the interdecadal change in the East Asian winter monsoon around the late 1990s. Clim Environ Res 21(2):197-209. https://doi.org/10.3878/j.issn.1006-9585.2015.15169 (in Chinese)

Xie SP, Deser C, Vecchi GA, Ma J, Tenf H, Wittenberg AT (2010) Global warming pattern formation: sea surface temperature and rainfall. J Clim 23(4):966-986. https://doi.org/10.1175/2009J CLI3329.1

$\mathrm{Xu} \mathrm{CH}, \mathrm{Xu}$ Y (2012) The projection of temperature and precipitation over China under RCP scenarios using a CMIP5 multimodel ensemble. Atmos Ocean Sci Lett 5(6):527-533. https:// doi.org/10.1080/16742834.2012.11447042

Yang X, Li DL, Tang X (2014) Probability assessment of temperature and precipitation over China by CMIP5 multi-model ensemble. J Desert Res 34(3):796-804. https://doi.org/10.7522/j. issn.1000-694X.2013.00381

Zhang WJ, Tan GR (2012) Simulated changes of land surface water associated with global warming over China. Trans Atmos Sci 35(5):550-563. https://doi.org/10.1007/s11783-011-0280-z

Zhang Y, Sperber KR, Boyle JS, Dix M, Ferranti L, Kitoh A, Lau William KM, Miyakoda K, Randall D, Takacs K, Wetherald R (1997) 
East Asian winter monsoon: results from eight AMIP models. Clim Dyn 13(11):797-820. https://doi.org/10.1007/s003820050 198

Zhang WL, Zhang JY, Fan GZ (2015) Evaluation and projection of dry-and wet-season precipitation in southwestern China using CMIP5 models. Chin J Atmos Sci 39(3):559-570. https://doi. org/10.3878/j.issn.1006-9895.1408.14136 (in Chinese)

Zhou TJ, Chen XL (2015) The uncertainty in the $2^{\circ} \mathrm{C}$ warming threshold issue as related to climate sensitivity and climate feedback. Acta Meteorologica Sinica 73(4):624-634. https://doi. org/10.11676/qxxb2015.057

Zhou B, Wang H (2008) Interdecadal change in the connection between Hadley circulation and winter temperature in East Asia.
Adv Atmos Sci 25(1):24-30. https://doi.org/10.1007/s0037 6-008-0024-6

Zhou T, Yu R (2006) Twentieth-century surface air temperature over China and the globe simulated by coupled climate models. J Clim 19(22):5843-5858. https://doi.org/10.1175/JCLI3952.1

Publisher's Note Springer Nature remains neutral with regard to jurisdictional claims in published maps and institutional affiliations. 